\title{
Prefrontal Cortical Deletion of DNA Methyltransferases Dnmt1 and Dnmt3a Reduces Palatable Food Intake
}

\author{
Jonathan Velasco Joy-Gaba \\ Cumberland, MD
}

Bachelor of Science, University of Maryland 2004

Master of Science Biological and Physical Sciences, University of Virginia 2011

A Dissertation presented to the Graduate Faculty of the University of Virginia in Candidacy for the Degree of Doctor of Philosophy

\author{
Department of Pharmacology \\ University of Virginia
}

December 2016

Michael Scott, Ph.D.

Douglas Bayliss, Ph.D.

Thurl Harris, Ph.D.

Jessica Connelly, Ph.D.

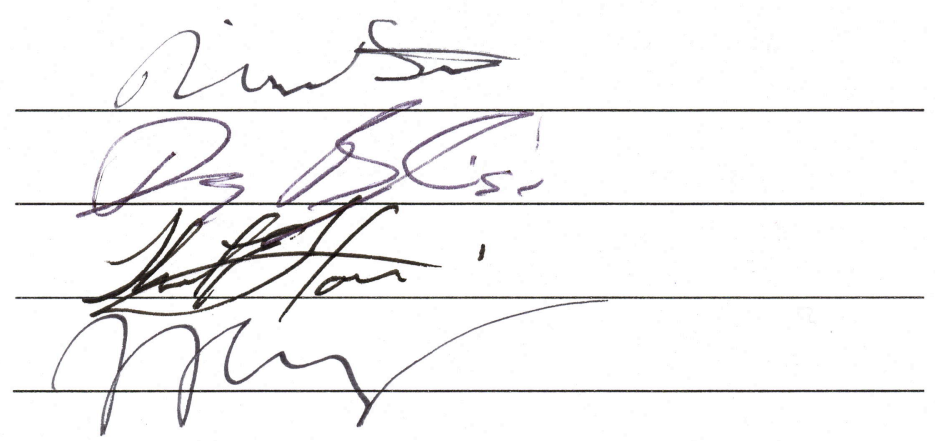




\begin{abstract}
DNA methylation is an epigenetic mechanism most often associated with the repression of gene expression; mediated by the DNA methyltransferases (DNMT). Expression of both DNMT1 and DNMT3a isoforms within post-mitotic neurons of the central nervous system (CNS) has been shown to be important in modulating the response to drugs of abuse and other stimuli that produce changes in neuronal plasticity. Interestingly, DNMT1 and DNMT3a expression has been shown to be dynamically regulated in the medial prefrontal cortex (mPFC), suggesting that these enzymes may also be involved in the modulation of mPFC dependent behavior. Indeed, obesity induces hypermethylation of the $\mu$ opioid receptor, suggesting that the modulation of methylation may represent an important mechanism engaged to produce changes in PFC function and thus behaviors. Based on these suggestions, we hypothesized that the DNMT enzymes in the PFC act to coordinate palatable food consumption. In a test of this hypothesis, we generated PFC-specific deletions of both the methyltransferases expressed in the CNS, DNMT1 and DNMT3a, and characterized their requirement in feeding behaviors. We demonstrate that animals lacking PFC-specific DNMT1 and DNMT3a showed a significant reduction in palatable food consumption, and that the intake of high-fat food showed less dependence on MPFC methylation state compared to a high fat and high carbohydrate food. Furthermore, the effect on behavior was selective on food intake, with no modulation on other PFC-dependent behaviors. Furthermore, we demonstrate a method to isolate discrete population of neurons
\end{abstract}


from tissue suitable for downstream molecular assays. Our data suggest for the first time that DNA methylation is required for appropriate regulation of palatable food intake. 


\section{Dedications}

I would like to first and foremost thank my mentor Michael Scott, whose guidance, wisdom, and support taught me to be a scientist. I appreciate all the patience you've shown me during the countless times that I bothered you in your office with crazy questions and seemingly terrible data. You have been the most kind, patient, and positive person I have ever met. Also, you have the uncanny ability to turn any worry into an inspiration. I wish there were a way to fully convey how thankful and appreciative I am to have been your graduate student.

I am grateful to Doug Bayliss, Jessica Connelly, Chein Li, and Wendy Lynch for serving on my committee and providing helpful feedback to ensure the scientific rigor of the work contained within this dissertation. A special thanks to Thurl Harris for subbing in to complete my committee at the time of my defense and for being an all-around positive spirit. Another special thanks to Paula Barrett, who played a major role in my transition to work with Michael Scott in the first place.

I would like to thank and acknowledge Dan Warthen and Brandon Newmyer, fellow members of the Scott Lab who helped me with the many surgeries needed for my experiments. To Mike McConnell, who's nuclei isolation protocol I adapted to validate my DNMT deletion. To the department of pharmacology, the system that exists to nurture science through seminars, journal clubs, and an all-around collaborative environment. A special thanks to Jolene Kidd, Tammy Snow, and the pharmacology department staff that keeps everything running smoothly. To Mike Solga and Claude Chew of the Flow 
Cytometry Core, your expertise was invaluable in helping me set-up and eventually sort my nuclei. To the mouse, whose ultimate sacrifice made this work even possible.

To my parents, Carmen and Vergel, who braved a new frontier and moved to this great nation seeking a better future for their children. You raised me to have a sense of pride in what I do, driving me to always do my best, and to live in manner than does not lead to regret. To my other parents, Lis and Jerry, who's faith in me can move mountains. Your love and support have been unwavering and I simply could not exist without your help.

To my cats, Charlie, Cassie, Ty, Ceebie, Smokey, and Tilly. Your furry little faces and soulful little eyes have all served as constant reminders of what is important in life. True to the quote on our bumper magnet, "Who rescued who?" you all have served as ambassadors and guardians for my soul. You have kept me balanced and relaxed, especially during periods of high stress with your unconditional love.

To my wife, Jennifer, I dedicate this dissertation to you. Without your love and support, completing this dissertation would not have been possible. You've changed my life in ways I never thought possible and though I shall try, words will never adequately express how grateful I am. You make me a stronger person. You live life through a perspective unlike no one else I know on Earth, and because of that, I look to you as a role model. You are fearless and strong, yet sweet and ever mindful of the needs of others. I am truly lucky and thankful to have you in my life. You fight for me and are always in my corner. My graduate 
career has been difficult, presenting on several occasions with scenarios that I

believe would have led most others to quit. I would have been unable to persevere without you. I love you. 


\section{Table of Contents}

Abstract.................

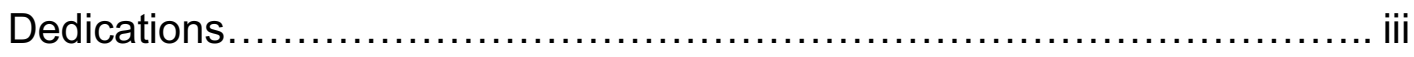

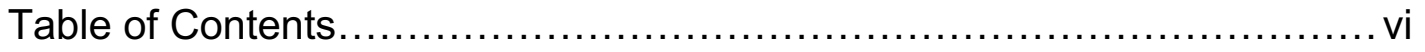

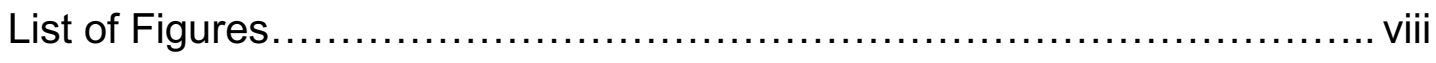

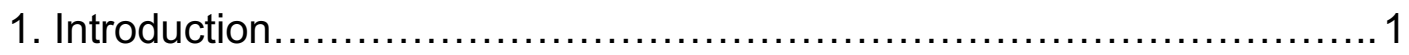

1.1. Homeostatic feeding controls ........................... 2

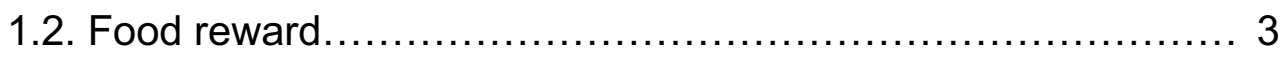

1.3. PFC control of reward seeking and feeding behaviors......... 5

1.4. DNA methylation and the regulation of neural activity $\ldots \ldots \ldots \ldots 7$

2. Specific Aim......................................................... 13

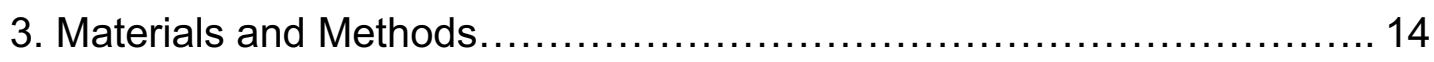

3.1. Animals and surgical manipulations........................ 14

3.2. FACS sorted isolation of frontal cortical nuclei............... 15

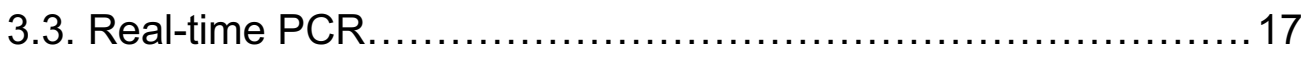

3.4. Tissue sectioning and Immunohistochemistry............... 18

3.5. Microscopic analysis..................................... 19

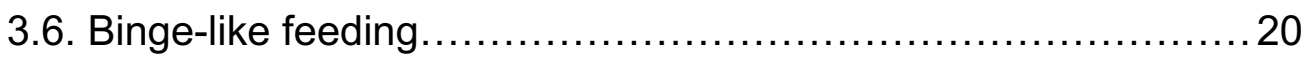

3.7. Daily food intake........................................ 20

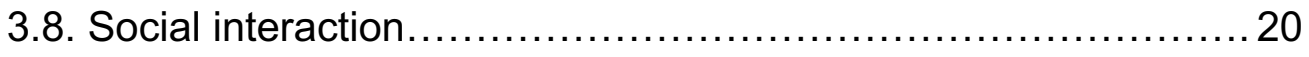

3.9. Sucrose preference........................................... 21

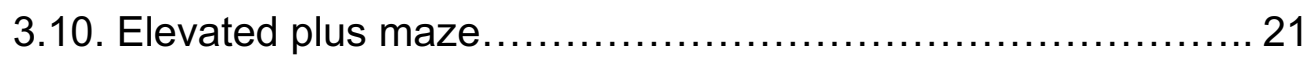

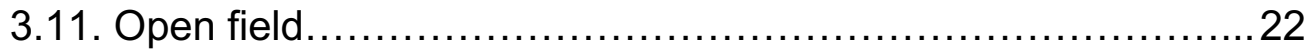


3.12. Forced Swim Task .......................................... 22

3.13. Novel object recognition task .............................. 22

3.14. Blood corticosterone measurements......................... 23

3.15. Statistical analyses........................................... 24

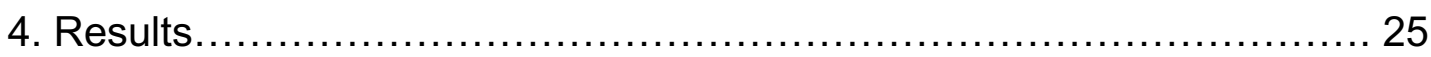

4.1. Isolation of GFP-positive nuclei.............................. 25

4.2. Validation of Frontal-cortical loss of Dnmt1 and Dnmt3a in mouse

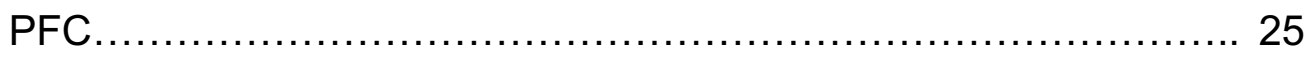

4.3. Frontal-cortical loss of Dnmt1 and Dnmt3a selectively suppresses palatable food intake.............................................. 26 4.4. FC loss of Dnmts does not affect emotional processing or novelty

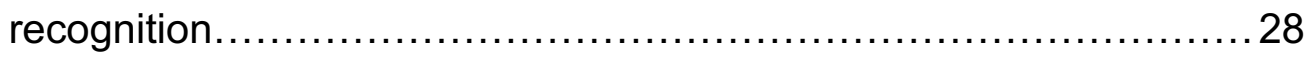

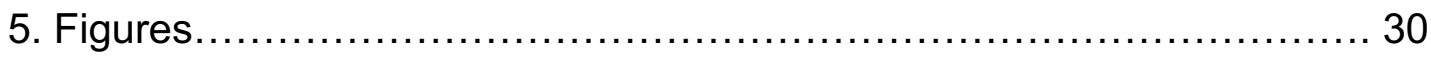

6. General Discussion and Conclusion

6.1. Discussion................................................... 39

6.2. Conclusion .................................................. 45

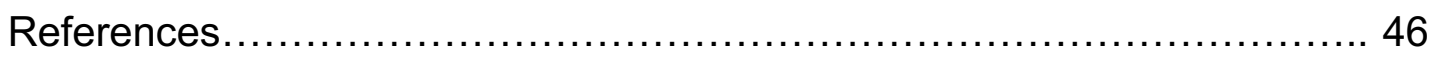




\section{List of Figures}

Figure 1. Flow cytometric profile of GFP-positive nuclei

Figure 2. Image stream of GFP-positive nuclei

Figure 3. Enrichment of GFP mRNA expression in FACS sorted nuclei

Figure 4. Schematic of Dnmt1 and Dnmt3a conditional alleles

Figure 5. Frontal-cortical expression of Cre-GFP produces mosaic knockdown of Dnmt1 and Dnmt3a in GFP-positive sorted nuclei

Figure 6. Frontal cortical loss of Dnmt1 and Dnmt3a selectively suppresses palatable food intake

Figure 7. Frontal cortical loss of Dnmt1 and Dnmt3a does not alter normal feeding behavior

Figure 8. FC loss does not affect novelty recognition or affect 


\section{Introduction}

The decision to eat may seem very simple, requiring little conscious effort. A normal individual's energy homeostatic system can control their behaviors on whether to eat, when to eat, and how much to eat in order to match their energy expenditure in an effort to maintain stable body weight and fat stores (Bray, Flatt, Volaufova, Delany, \& Champagne, 2008). The central regulation of energy balance has been well characterized and is achieved by a system in which circulating factors inform the brain of energy stores (Morton, Meek, \& Schwartz, 2014). The brain integrates this information and initiates appropriate behavioral, autonomic, and endocrine output. Originally, these systems evolved during a time when food was scarce, but the modern world offers an over-abundance of food. In the United States, approximately $69 \%$ of adults are overweight and approximately $36 \%$ of adults are obese (Flegal et al., 2012). There is overwhelming data associating many medical conditions with obesity, including metabolic disorders, cardiovascular disease, reproductive disorders, and several cancers (Flegal et al., 2012) and the medical costs associated with obesity is approximately $\$ 150$ billion (Finkelstein, Trogdon, Cohen, \& Dietz, 2009). As weight gain occurs when energy intake is greater than energy expenditure, much attention is being paid to either altering food consumption or increasing energy expenditure as the weight loss industry alone is worth over $\$ 60$ billion annually. In this dissertation, I focus my attention on improving our understanding on what factors may manipulate energy intake. 


\subsection{Homeostatic feeding controls}

There are several peripheral signals that can pass through the blood-brain barrier and act upon key feeding circuits located within the brain. The two moststudied signals are the adiposity negative feedback signals leptin and insulin. Leptin is secreted from adipose tissue in proportion to existing body fat mass and acts on neurons that regulate energy balance by reducing food intake (Considine et al., 1996). Impairment within the leptin signaling system can promote hyperphagia and substantial weight gain. Indeed, there are two monogenic mouse models, the leptin deficient $o b / o b$ mouse and the leptin receptor deficient $d b / d b$ mouse, that display pronounced hyperphagia (Chen et al., 1996; Ingalls, Dickie, \& Snell, 1950). The other adiposity negative feedback signal insulin is secreted by the pancreas, found circulating in proportion to the body's fat stores, and can act on neurons to reduce food intake (Woods, Lotter, McKay, \& Porte, 1979). If insulin signaling is reduced in the brain, the result is increased food intake and weight gain (Brüning et al., 2000).

In addition to the adiposity negative feedback signals, there are gut peptides that signal the perception of satiety and help determine the amount of food consumed during a feeding session. These signals include peptide YY (PPY), glucagon-like peptide 1 (GLP1) and cholecystokinin (CCK) and along with gastric distention, can signal the termination of a meal (Batterham et al., 2002; Gibbs, Young, \& Smith, 1997; Turton et al., 1996). Conversely, ghrelin is a hormone that is secreted by the gastrointestinal track prior to a meal and serves to stimulate feeding (Tschöp, Smiley, \& Heiman, 2000). 
The hypothalamic area in the brain plays a key role in the regulation of feeding behaviors. Hormonal and nutrient-related peripheral signals cross the blood-brain barrier and act on key neurons to regulate feeding (Schwartz, Woods, Porte, Seeley, \& Baskin, 2000). The arcuate nucleus is one of several nuclei of the hypothalamus and contains two primary populations of neurons with two opposing effects on feeding behavior. In general, neurons expressing agoutirelated protein (AGRP) and neuropeptide Y (NPY) stimulate feeding when activated and are orexigenic (Satoh et al., 1997; Schwartz, Hahn, Breininger, \& Baskin, 1998). These neurons are inhibited by signals that reduce feeding such as leptin and insulin, and are activated by signals that increase feeding such as ghrelin (Schwartz et al., 2000). In contrast, neurons expressing proopiomelanocortin (POMC) release $\alpha$-melanocyte stimulated hormone ( $\alpha-\mathrm{MSH}$ ) and are stimulated by anorexigenic signals such as leptin and inhibit food intake (Cowley et al., 2001). NPY and POMC neurons of the arcuate nucleus do not have exclusive control on hunger. Expression of leptin receptors are also found in other hypothalamic areas such as the ventromedial, dorsomedial, premammillary nuclei, lateral, and perifornical areas where they also contribute to leptin's effects on food intake (G. M. Leinninger \& Myers, 2007).

\subsection{Food reward}

These hormonal and nutrient-related signals provide information on hunger and satiety, but do not necessarily influence the choice of food consumed. For instance, how exactly does one decide to eat something for 
breakfast? What factors play into deciding between choices like a donut, fruit, eggs, or oatmeal? Interestingly, delivery of electrical stimulation to the lateral hypothalamus elicits food intake and rats will learn to self-administer for electrical stimulation (Hoebel \& Teitelbaum, 1962). Anatomical evidence supports the notion that the lateral hypothalamus works in concert receiving nutritional information from the arcuate nucleus and other hypothalamic and brainstem areas with inputs from the mesolimbic dopaminergic system and prefrontal cortex to affect motivational feeding (Elmquist, Elias, \& Saper, 1999; Grill \& Kaplan, 2002; Gina M Leinninger et al., 2009; Risold, Thompson, \& Swanson, 1997; Swanson, 2000; Wise, 1974). The natural reward system has evolved to influence behavior to promote a species' own survival by interpreting hedonic, motivational, and incentive values of environmental stimuli (Berridge \& Kringelbach, 2008; Schultz, 2007; Wise, 2004, 2006), and the perception of taste serves as the primary sensory input for providing reward or punishment for foods consumed (Rolls \& Bell, 1999).

It is well described for drugs of abuse that repeated exposure can lead to increases in hedonic capacity (reduced reward) and drive increased drug intake (Ahmed, Kenny, Koob, \& Markou, 2002; Koob \& Le Moal, 2005, 2008; Russo et al., 2010). In regards to food intake, palatability plays an important role in determining what is eaten and highly palatable foods can even prompt overconsumption when energetic needs are already met. There is a body of evidence that repeated exposure to palatable food can lead to similar neuroadaptive changes and behavioral dependence as seen in drug addiction. For instance, 
repeated sucrose access can upregulate dopamine release (Avena, Rada, \& Hoebel, 2008), upregulate dopamine transporter (Bello, Sweigart, Lakoski, Norgren, \& Hajnal, 2003), and alter dopamine D1 and D2 receptor signaling in the nucleus accumbens (Avena et al., 2008; Bello, Lucas, \& Hajnal, 2002). Furthermore, extended access to palatable diet led to sustained hyperphagia (Johnson \& Kenny, 2010), and abstinence from sucrose can develop withdrawal symptoms (Avena et al., 2008).

Interestingly, there are several key clinical aspects of drug addiction can be drawn in parallel to overeating palatable foods. Binge eating disorder is an eating disorder characterized with reoccurring episodes of excessive food consumption accompanied with a sense of loss of control. Women with binge eating disorder (BED) have symptoms that meet the criteria for addiction, such has having the loss of control of eating, having increased consumption of food, increased compulsive eating episodes, withdrawal of social activities, and further consuming food to cope with depressed feelings (Cassin \& von Ranson, 2007).

\subsection{PFC control of reward seeking and feeding behaviors}

The prefrontal cortex (PFC) has long been described as an important regulator of feeding and reward-seeking behaviors. Human imaging studies have demonstrated that the PFC is activated when the subject is stimulated with foods. For instance, the PFC activates upon viewing images of high-calorie foods (Killgore et al., 2003), and the PFC responds to the odors and flavor of a palatable drink when it is being consumed (Small, Veldhuizen, Felsted, Mak, \& 
McGlone, 2008). There are abundant clinical reports that demonstrate the involvement of the PFC in altered eating behavior. Hyperphagia is a clinical sign for several frontal lobe dysfunctions including fronto-temporal dementia (Ikeda, Brown, Holland, Fukuhara, \& Hodges, 2002), Klein-Levin syndrome (Landtblom, Dige, Schwerdt, Safstrom, \& Granerus, 2002), and the "Gourmand syndrome" (Regard \& Landis, 1997). In fact, impairment in executive function, specifically inhibitory control, is a typical component found in many eating disorders (Van den Eynde et al., 2011).

Interestingly, manipulations within the PFC can alter food intake. Administering $\mu$-opioid receptor agonists in the PFC induces binge-like hyperphagia (Mena, Sadeghian, \& Baldo, 2011) with $\mu$-opioid receptor antagonists producing the opposite effect (Blasio et al. 2013). Further, optogenetic stimulation of PFC dopamine D1 receptor expressing neurons increases food intake of both grain pellets and high caloric diet in stated animals (Land et al., 2014), a process that likely also involves the activation of disinhibitory neurons within the PFC (Gaykema et al., 2014).

The PFC is reciprocally connected to the basolateral nucleus of the amygdala (BLA)(Kita \& Kitai, 1990; Shi \& Cassell, 1998). Interactions among the PFC and BLA may mediate impulsive and compulsive behaviors associated with addictive behaviors (Chudasama et al., 2003; Torregrossa, Quinn, \& Taylor, 2008). The PFC also sends strong projections to the lateral hypothalamus and Acb shell (Gabbott, Warner, Jays, Salway, \& Busby, 2005; Vertes, 2004). 
Stimulating glutamate receptors within the LH induces hyperactivity and strong feeding responses (Stanley et al., 1996).

Taken together, altered PFC function produces a change in food reward salience that drives hyperphagia, and may lead to the development of feeding disorders and obesity (Contreras-Rodríguez, Martín-Pérez, Vilar-López, \& Verdejo-Garcia, 2015; Gálosi et al., 2015; Heni et al., 2014; Lavagnino, Arnone, Cao, Soares, \& Selvaraj, 2016; Marsh et al., 2009; Uher et al., 2004).

\subsection{DNA methylation and the regulation of neural activity}

While much is known regarding the neuronal populations of the frontal cortex that control feeding behavior, the molecular mechanisms that modulate their function and regulate behavioral output are not as well described, preventing a better understanding of how diseases of disordered feeding develop. Recent data suggest that epigenetic DNA modifications play an important role in shaping the function of the frontal cortex. DNA methylation refers to the addition of a methyl group to the fifth carbon of a cytosine that precedes a guanine in DNA (CpG). Most of the time, CpG dinucleotides appear in CG-rich DNA sections known as CpG islands. $\mathrm{CpG}$ islands are often found clustered within control regions of a gene, such as the promoter, but can also be found in the gene's exons and introns (Gardiner-Garden \& Frommer, 1987). DNA methylation has many functions including the silencing of transposable elements and the transcriptional suppression of a large number of genes (Holliday \& Pugh, 1975). 
The DNA methyltransferases (DNMT) mediate the addition of a methyl group to cytosine. The initial addition of the methylation mark is mediated by the de novo DNA methyltransferase DNMT3a. The methylation mark is perpetuated by the maintenance activity of DNMT1, which recognizes hemi-methylated DNA and methylates the complementary strand during DNA replication producing a dimethylated mark (Feng et al., 2010). Expression of DNMT1 and DNMT3a isoforms are found within post-mitotic neurons of the frontal cortex, suggesting that DNMTs play a role in regulating neuron activity and subsequent behaviors (Feng, Chang, Li, \& Fan, 2005; Inano et al., 2000; Veldic et al., 2004).

Significant plasticity in the degree of methylation has been observed in the rodent PFC, suggesting that modulation of methylation may represent an important mechanism engaged through reward exposure to produce changes in PFC function and thus behavior. For instance, nicotine has been shown to upregulate the expression of the GABA neurotransmitter synthetic enzyme GAD67 through a decrease in promoter methylation in the PFC (Satta et al., 2008a). Interestingly, high fat diet promotes hypermethylation of the mu-opioid receptor promoter in the PFC when compared to chow fed animals (Vucetic, Kimmel, \& Reyes, 2011).

Since the initial observation that active DNA methylation was involved in long term potentiation and memory formation (Levenson et al., 2006; Lubin, Roth, \& Sweatt, 2008; Marsh et al., 2009; Miller \& Sweatt, 2007), interest in investigating DNA methylation within the CNS has grown. There are two main approaches to investigating changes in DNA methylation in the brain. One 
approach utilizes pharmacological inhibitors of the DNA methytransferase enzymes such as furan or 5-AzaCytidine. These inhibitors can be targeted to specific areas of the brain and can control when DNA methylation is interrupted. However, limitations to this approach include the lack of specificity to distinguish among the various DNMT isoforms and the DNMT inhibitors present potential toxic effects on protein translation which further complicates results (Jüttermann, Li, \& Jaenisch, 1994).

Genetic approaches have also been developed to investigate the significance of DNA methylation. Mice with mutations in any of the three functional Dnmts (Dnmt1, Dnmt3a, and Dnmt3b) are not viable (Li, Bestor, \& Jaenisch, 1992; Okano, Bell, Haber, \& Li, 1999). Therefore, conditional knockout mice were generated in order to study the function of DNA methylation in the central nervous system (Fan et al., 2001; Golshani, Hutnick, Schweizer, \& Fan, 2005; Hutnick et al., 2009; Nguyen, Meletis, Fu, Jhaveri, \& Jaenisch, 2007).

Together, both approaches have demonstrated that DNA methylation is necessary for memory formation and consolidation (Day et al., 2013; Feng et al., 2010; Maddox \& Schafe, 2011; Miller \& Sweatt, 2007) with a reduction in DNA methylation leading to enhanced glutamatergic synaptic scaling (Meadows et al., 2015) and increased neuronal excitability (Meadows et al., 2016).

In the field of neuroepigenetics, there is interest in understanding of the genome-wide effects of DNA methylation between smaller, discrete populations of cells. The brain is a collection of highly specialized cell types that functionally work in concert to perform specialized electrophysiological behavior, as well as 
continue to fulfill normal metabolic needs and pathogenic defense. Cells within the brain have classically been characterized by location, morphology, electrophysiological characteristics, chemical target characteristics, and molecular markers (Molyneaux, Arlotta, Menezes, \& Macklis, 2007) and in situ hybridization has demonstrated widespread regional heterogeneity (Lein et al., 2007).

A major limitation in understanding molecular mechanisms for a particular area are that assays end up being representative average of a heterogeneous population of neurons and cell types. Isolation of neurons present unique challenges compared to other tissues in the body in that they are highly interconnected and are damaged upon physical separation. Several methods exist that allow for isolation of small or single cell populations such as laser capture microdissection (W.-Z. Wang et al., 2009), transcriptome in vivo analysis (TIVA)(Lovatt et al., 2014), or single neuron extraction by glass microcapillary or laser microdissection (Citri, Pang, Südhof, Wernig, \& Malenka, 2011; Lovatt, Bell, \& Eberwine, 2015). All these methods are limited to small numbers of cells, can be low throughput, and are intrinsically difficult to get large enough amounts of high quality material for unbiased methods such as RNA-Seq. Development of robust methods to quantitatively interrogate the genome-wide effects of discrete CNS populations remain to be an area of growth. A recent approach used an alternative high throughput method by dispersing cells and later separating by fluorescence-activated cell sorting (FACS)(Zeisel et al., 2015). However, the authors used a proteolytic degradation of surface proteins dispersion method 
which can greatly alter gene expression (H.-L. Huang et al., 2010). Recently, a protocol has been developed to isolate nuclei from brain tissue and sort using fluorescence-activated cell sorting, avoiding the harsh treatments discussed above (Grindberg et al., 2013). Certainly, mRNA isolated from the nuclei can be used for downstream molecular assays. The protein coding mRNA are transcribed from DNA and processed within nucleus, then exported to cytoplasm for further processing and maturation. Mature mRNA is imported back and can accumulate in the nucleus (Weil, Boutain, Audibert, \& Dautry, 2000). The nuclear mature mRNA and whole cell transcriptome are similar and suitable for RNASeq, though transcripts coding for protein families involved in cell cycle, mitosis, and transcription are enriched within the nuclear transcriptome (Grindberg et al., 2013).

Consequently, based on the importance of the methyltransferases in controlling neuronal plasticity and excitability and data suggesting that DNA methylation in the prefrontal cortex could significantly affect feeding behavior (Vucetic, Kimmel, Totoki, Hollenbeck, \& Reyes, 2010) we hypothesized that the Dnmt enzymes in the frontal cortex are important modulators of palatable food consumption. In a test of this hypothesis, we generated frontocortical-specific deletions of Dnmt1 and Dnmt3a and characterized their role in the regulation of feeding behavior. Unexpectedly, we observed that deletion of both Dnmt1 and Dnmt3a produced a blunting of unlearned palatable food binging behavior, in the absence of an effect on low sugar, low fat, grain based chow intake. No change in affect (depression like behavior, anxiety-like behavior), locomotion or social 
behavior was observed. Our work demonstrates that selective behaviors

modulated by the frontal cortex are differentially sensitive to expression levels of the principal DNA methyltransferases, DNMT1 and DNMT3a. 


\section{Specific Aim}

Reward expectancies through processes of learning and memory serve as powerful motivators that drive hedonistic food intake and drug abuse. The learning and memory field recognizes the importance of transcriptional regulation during memory formation, but exactly how transcriptional regulation occurs is poorly understood. Interestingly, there is a growing body of evidence that implicates epigenetic mechanisms that alter gene expression patterns and subsequent behavior. Epigenetics is important in normal development as it provides "cellular memory" during mitosis through posttranslational modifications to DNA and chromatin. Though DNA methylation is a static process in development, recent evidence demonstrates that DNA methylation is dynamically regulated in the adult nervous system and implicates this cellular mechanism as a crucial step in memory formation. Gaining an understanding of the requirement for neuronal DNA methytransferase expression in the modulation of feeding behaviors may provide insight on previously unidentified mechanisms that functionally serve to create behavioral change.

In my thesis studies, I propose determine whether palatable food intake is dependent on DNA methylation within the prefrontal cortex 


\section{Materials and Methods}

\subsection{Animals and surgical manipulations}

We used the cre/loxP system to generate conditional Dnmt1, Dnmt3a, and Dnmt1 + Dnmt3a deletions. The loxP-flanked Dnmt1 and Dnmt3a homozygous mice have been described previously resulting in a catalytically inactive DNA methyltransferase (Dodge et al., 2005; Fan et al., 2001; Feng et al., 2010). The Dnmt 1 conditional allele have exons 4 and 5 flanked by loxP sites. Cre-mediated deletion of exons 4 and 5 lead to out-of-frame splicing from exon 3 to exon 6 , resulting in a null Dnmt1 allele (Jaenisch et al., 2001). The Dnmt3a conditional allele has exon 19 contained within the floxed region. To localize gene deletion in frontal cortical tissue, mice were stereotactically injected with an adenoassociated virus expressing the gene encoding Cre recombinase fused to GFP under the control of the synapsin-1 promoter (AAV2.1-Syn-Cre-GFP, University of North Carolina Gene Therapy Vector Core) into the medial pre-frontal cortex (mPFC) of Dnmt1 and Dnmt3a floxed male mice. The synapsins are a family of neuronal phosphoproteins that are found in the cytoplasmic region of small presynaptic vesicles (Thiel, 1993) and viral expression driven by the synapsin-1 promoter drives expression in excitatory pyramidal neurons.

All subjects are grouped housed on sani-chip bedding on a 12 hour light cycle (lights on 6am to 6pm) and fed ad libitum on TD7912 unless otherwise noted. Animals $6-8$ week old $(25-30 \mathrm{~g})$ were anesthetized with a mixture of ketamine/dexmedetomidine (40 mg/kg / $0.4 \mathrm{mg} / \mathrm{kg}$ given i.p.) followed by inhalation of $1 \%$ isoflurane gas anesthesia. $200 \mathrm{nl}$ of AAV2.1-Synapsin-Cre-GFP 
was delivered to the mPFC bilaterally (coordinates: $\mathrm{AP}=2.05, \mathrm{ML}=+/-0.35$, and dura DV = -1.5 from Bregma). Immediately following surgery, mice received subcutaneous injections of antesedan $(0.4 \mathrm{mg} / \mathrm{kg})$ and ketoprofen $(0.1 \mathrm{ml}$ of 1 $\mathrm{mg} / \mathrm{ml})$. Mice were observed 5 days post-surgery and received ketoprofen subcutaneously as needed.

\subsection{FACS sorted isolation of frontal cortical nuclei}

Mice were anaesthetized with $0.12 \mathrm{~mL}$ euthanasia solution (mix information) i.p., immediately followed by by cervical dislocation and decapitation. Unfixed PFC tissue from DNMT1 and DNMT3a floxed animals injected with CreGFP and from control wildtype mice injected with Cre-GFP was roughly harvested, snap frozen in liquid nitrogen, and stored at $-70^{\circ} \mathrm{C}$ until further processing.

Batches of tissue punches were processed for nuclear isolation according to a prior published protocol (Grindberg et al., 2013). All reagents were prepared the day of isolation using molecular grade nuclease-free water and stored on ice throughout the entire course of the protocol. The protease inhibitor used was made by Roche (cat\# 04693124001). The lodixanol solutions were prepared by diluting 60\% lodixanol (Sigma, cat\# D1556-250mL) in OptiPrep Diluent for Nuclei

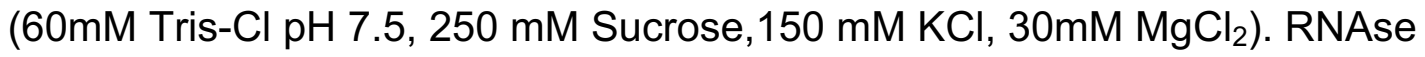
inhibitors can be added to working solutions, but we found they were unnecessary. Individual tissue punches were incubated in Nuclei Isolation Medium (10 mM Tris-Cl pH 7.5, $250 \mathrm{mM}$ Sucrose, $25 \mathrm{mM} \mathrm{KCl,} 5 \mathrm{mM} \mathrm{MgCl}_{2}, 1 \mathrm{mM}$ 
dithiothreitol, $1 \mathrm{X}$ protease inhibitor). Tissue is passed through a $1 \mathrm{~mL}$ pipette tip several times and is then homogenized using a polytron. Detergent $(0.1 \%$ TritonX100) is added and Dounce homogenized using two pestles of decreasing size. Homogenized tissue is strained through a 70um filter (Falcon, cat\# 352350) and is centrifuged for 15 minutes at $1400 \mathrm{xg}$ at $4^{\circ} \mathrm{C}$. The supernatant is removed and sample containing nuclei is resuspended in $500 \mathrm{uL}$ of nuclei isolation medium, followed by the addition of $50 \%$ lodixanol solution to make a final concentration of $25 \%$ lodixanol. The sample containing nuclei and $25 \%$ lodixanol is carefully layered on $1 \mathrm{~mL}$ of $29 \%$ lodixinol in a $4 \mathrm{~mL}$ ultracentrifuge tube and centrifuged at $10,300 \mathrm{x} \mathrm{g}$ for 20 minutes at $4^{\circ} \mathrm{C}$. Supernatant is then extracted and nuclei were resuspended in $500 \mathrm{uL}$ nuclei storage buffer (PBS, 1X protease inhibitor). The nuclei concentration was determined, and stored on ice for fluorescently activated cell sorting.

To isolate nuclei from excitatory neurons of the PFC that were either wildtype for Dnmt1 and Dnmt3a or showed loss of Dnmt1 and Dnmt3a, we performed fluorescently activated nuclear sorting. Neuronal nuclei with loss of Dnmt1 and Dnmt3a can be selected by following the expression of GFP, which is fused to the Cre recombinase gene and therefore targeted to express within the nucleus. We chose to selectively isolate pyramidal neurons for our comparison using the SATB2 transcription factor previously described to be exclusively expressed in excitatory cortical neurons (Y. Huang et al., 2013), as these cells for the principle output cell type of the MPFC and have been shown to be sensitive to epigenetic change. Furthermore, this allowed selection of only neurons to 
serve as controls to our GFP-positive nuclei. So, to select for excitatory neuronal nuclei that expressed GFP from the Cre recombinase gene, nuclei were incubated for 1 hour with Dapi and anti-SATB2 (1:100, abcam ab34735) conjugated to R-Phycoerythrin (RPE) using the lightning-link RPE conjugating kit, (Innova Biosciences), performed as per manufacturer's instructions. Thus, gating for GFP, RPE and DAPI using an Influx cell sorter or Aria Fusion cell sorter (BD Biosciences) allowed us to obtain excitatory neuronal nuclei from the control wildtype tissue and from the Dnmt1 and Dnmt3a floxed PFC tissue for comparison. FACS sorting will be performed by the University of Virgina Flow Cytometry Core Facility, using a Becton Dickinson FACSVantage SE Turbo Sorter with DIVA Option. The GFP signal (from the Cre-GFP fusion protein) and the Alexa 594 nuclear antigen signal will be used to gate populations of nuclei. FACS sorted nuclei were spun down for 10 minutes at $500 \times$ g, supernatant removed, snap-frozen in liquid nitrogen, and stored at $4^{\circ} \mathrm{C}$ overnight for further processing.

\subsection{Real-time PCR}

cDNA was prepared from the isolated GFP expressing nuclei using the Taqman Gene Expression Cells to CT kit (ThermoFisher, cat\# 4399002) per manufacturer's instructions. Taqman assays for Dnmt1 (Mm01151063_m1) and Dnmt3a (Mm00432881_m1) were used to quantify loss of methyltransferases expression. The 18S (Hs99999901_s1) taqman assay was used to normalize expression between samples. Fold mRNA expression was calculated using the 
delta-delta CT method. All PCR reactions were performed using the MyIQ Single Color Real-Time PCR detection system (Bio-Rad).

\subsection{Tissue sectioning and Immunohistochemistry}

Mice were anaesthetized with $0.12 \mathrm{~mL}$ of euthasol (pentobarbital) i.p. and underwent trans-cardiac perfusion with buffered saline followed by fixative solution ( $4 \%$ paraformaldehyde in $0.1 \mathrm{M}$ phosphate buffer, $\mathrm{pH} 7.4$, containing $15 \%$ saturated picric acid). Mice were perfused with $50 \mathrm{ml}$ of fixative for 5 minutes. Following perfusion, brains were removed and immersed in the same 4\% paraformaldehyde fixative solution overnight, after which time they were transferred to a solution of $0.1 \mathrm{M}$ phosphate buffer. Brains were blocked coronally using a mouse brain mold. Tissue was blot-dried and arranged into standard cryomolds (Tissue Tek, \#4557) with all brain sections in a single cryomold. The molds were then filled with warmed $10 \%$ gelatin solution, allowed to cool to solidify, and immersed into refrigerated $4 \%$ paraformaldehyde solution overnight. The blocks were then removed from the molds, trimmed, glued on polystyrene dishes, and cut into coronal sections (40 $\mu$ m thick). Brain sections were then collected serially in six-well tissue culture plates such that each well contained a representative series of the frontal cortex, with the distance between adjacent sections in each well being $240 \mu \mathrm{m}$. Sections were stored at $4{ }^{\circ} \mathrm{C}$ in $0.1 \mathrm{M}$ phosphate buffer containing $0.1 \%$ sodium azide as a preservative prior to the immunohistochemical procedures. One series of sections was used to examine GFP immunoreactivity and viral expression. Phosphate-buffered saline (PBS) 
was used to wash tissue slices during the immunohistochemical procedure, whereas all antibody incubation solutions were made in PBS containing $0.5 \%$ Triton $\mathrm{X}-100,0.1 \%$ sodium azide, and $1 \%$ normal goat serum. Initially, sections were pretreated with sodium borohydride $(0.1 \%)$ in PBS for 20 minutes followed by immersion into $0.3 \%$ hydrogen peroxide and $0.1 \%$ sodium azide in PBS ( 30 minutes) to quench endogenous peroxidase activity. Next, the sections were immersed in blocking solution containing $2 \%$ normal goat serum and Fab' fragments of goat anti-mouse IgG (Jackson Immunoresearch, \#115-007-003, 1:1,000) overnight at $4{ }^{\circ} \mathrm{C}$. Thereafter, sections were incubated overnight at $4{ }^{\circ} \mathrm{C}$ in rabbit anti-GFP (Clontech, \#632592, 1:5,000) followed by overnight incubation at $4{ }^{\circ} \mathrm{C}$ in biotinylated goat anti-rabbit IgG (Jackson Immunoresearch, \#111-065144 1:1,000).. Subsequently the sections were immersed in avidin-biotinperoxidase complex diluted in PBS with $0.1 \%$ Triton X-100 (ABC Elite kit, Vector; $1: 1,000)$ overnight at $4{ }^{\circ} \mathrm{C}$. Staining was completed using nickel-enhanced 3,3 'diaminobenzidine (DAB, $0.02 \%$, nickelous ammonium sulfate $0.15 \%$ ) in Tris- $\mathrm{HCl}$ (0.05M, $\mathrm{pH} 7.6)$ yielding a black reaction product. Sections from each well were then mounted in sequential order, air-dried, dehydrated through a series of graded ethanol concentrations, cleared in xylene, and coverslipped in DPX.

\subsection{Microscopic analysis}

The sections were examined with an Olympus BX51 microscope using a $4 x$ objective and digital images were captured using a Magnafire digital camera (Optronics, Goleta, CA) and stored in TIFF format. 


\subsection{Binge-like feeding}

Animals were individually housed on sani-chip bedding in the presence of a $100 \mathrm{~mm}$ petri dish bottom and allowed to habituate for 3 days prior to the feeding assay. One day prior to binge feeding, subjects are offered a small $(\sim 0.25 \mathrm{~g})$ sample of either a new piece of chow, Surwit diet (HFD; $58 \%$ of $\mathrm{kcal}$ obtained from fat, $25.5 \%$ of kcal obtained from carbohydrate (mostly sucrose), Research Diets Inc., \#D12331, $5.56 \mathrm{kcal} / \mathrm{g}$ ), or Western Diet (WD; 42\% of kcal obtained from fat, $42.7 \%$ of kcal obtained from carbohydrate (mostly sucrose), $4.41 \mathrm{kcal} / \mathrm{g}$ ) on the petri dish. At lights on the next day, a new full pellet of regular chow or HFD or WD was placed in the petri dish and subjects are allowed to free feed for 60 minutes. The binge feeding assay was subsequently repeated for 2 subsequent days.

\subsection{Daily food intake}

Subjects were individually housed and food consumption was monitored daily for 5 days.

\subsection{Social interaction}

Subjects were allowed to explore a 41 "x41" open square arena with a perforated acrylic cell located in the center of one of the arena walls for 2.5 minutes. Immediately following this session, a novel mouse was placed in the perforated cell and subjects are once again allowed to explore the arena for 2.5 minutes. Subjects always entered the arena in the far corner opposite of the 
perforated cell. EthoVision tracking software (Noldus) was used to capture mouse position within the arena. The arena was subdivided into the following regions: interaction zone, periphery, and corners and data was presented as a time ratio of time spent within the interaction zone with and without the novel mouse.

\subsection{Sucrose preference}

Subjects were given free access to two sipper tubes, one containing sucrose and the other water, for 14 days. Sipper tube position was alternated daily. For the first 3 days, both tubes were filled with water (baseline). Subjects were then exposed to increasing concentrations of sucrose solutions: days 4-6 $0.5 \%$ sucrose, days $8-101.0 \%$ sucrose, and days $12-142.0 \%$ sucrose. On days 7 and 11 between sucrose concentrations, both sipper tubes were filled with water.

\subsection{Elevated plus maze}

Subjects were allowed to explore an elevated plus maze (open arms and closed arms were both 24 inches in length) for 5 minutes. Mouse location was tracked using the EthoVision tracking system as described above. The elevated plus maze was subdivided into three regions closed arms, open arms, and center. Data is presented as time spent in either the closed or open arms. 


\subsection{Open field}

Subjects were allowed to explore a 41"x41" open square arena for 5 minutes. Mouse location was tracked using the EthoVision tracking system as described above and the arena was subdivided into regions (center and periphery). Data is presented as time spent within the defined region and distance travelled.

\subsection{Forced Swim Task}

Glass beakers $(4 \mathrm{~L})$ were filled with $3 \mathrm{~L}$ of room temperature water $(24-$ $26^{\circ} \mathrm{C}$ ). Mice were placed in the water and observed for 6 minutes by 3 trained and blinded observers. Following session, mice were returned to home cage. Following an initial 2 minute acclimation period, immobility time was scored during the final 4 minutes. The mouse was considered immobile when only one limb was used to maintain flotation. Latency to immobility was scored as length of time following the initial acclimation until first immobility period.

\subsection{Novel object recognition task}

The novel object recognition task was performed as previously described (Frick \& Gresack, 2003). During testing, subjects complete seven successive trials in a single day. Trials are 5 minutes in duration with 3 minutes rest between each trial at which time the subject is returned to its home cage. The arena and objects are cleaned with Minncare cold sterilant during the rest period. At the start of the experiment during trail 1 , subjects were placed in an empty 41 "x 41 " 
open arena and allowed to move freely and explore. During trails $2-4$, three different objects were each placed near separate corners and the subject was placed in the empty corner and allowed to explore the arena and objects. Response to spatial novelty was measured during trial 5 when one of the objects was displaced to a new location. Trial 6 was a repeat of trial 5 to allow the subject to habituate to object locations. Object novelty was measured in trial 7 by replacing one of the unmoved objects with a fourth distinct object. The EthoVision tracking system was used to collect duration and frequency of object exploration during each trial.

\subsection{Blood corticosterone measurements}

For baseline corticosterone measurements, subjects were habituated for 3 days to the restraint device and tail massage motion. On the 4th day, whole blood samples were collected via tail vein in non-heparin glass capillary tubes and transferred to microcentrifuge tubes during the late afternoon $(4 \mathrm{pm}-5 \mathrm{pm})$. On the 5th day, whole blood samples were collected again during the morning (7am8am) via tail vein. For corticosterone measurements under acute stress, mice were placed in restraints fashioned from modified $50 \mathrm{~mL}$ conical tubes for 30 minutes. There was a two week refractory period between baseline and acute stress measurements. Whole blood samples were immediately collected at the end of the 30 minute session. Blood serum was isolated from whole blood samples by incubating samples at room temperature for 10 minutes followed by 10 min of centrifugation at $2000 \times \mathrm{x}$ in $4^{\circ} \mathrm{C}$. Serum was pipetted off and stored at - 
$20^{\circ} \mathrm{C}$ for further analysis. Corticosterone was assayed using the Corticosterone rat/mouse ELISA (Immuno-Biological Laboratories Inc., \#IB79175) following the manufacturer's protocol.

\subsection{Statistical analyses}

Data are presented as mean \pm SEM (represented as error bars).

Validation of GFP-positive nuclei (Figure 3), validation of Dnmt1 and Dnmt3a deletion in GFP-positive enriched nuclei (Figure 5C), and comparison of palatable diets on binge-like feeding (Figure 6B) data were analyzed using ttests. The data for comparing binge-like feeding on HFD between single deletions and combined (Figure 6A), binge-like feeding over 3 days for HFD and WD (Figures 6C, 6D), and sucrose preference (Figure 8A) were analyzed using 2way ANOVAs. 


\section{Results}

\subsection{Isolation of GFP-positive nuclei}

The use of FACS nuclear sorting will allow us to isolate only those nuclei expressing viral Cre recombinase and thus showing (in the great majority) DNMT deletion (unless from WT animals). Since our Cre recombinase is tagged with GFP, we first validated whether the GFP signal can be detected by flow cytometry. Mice received prefrontal cortical (PFC) injections of Synapsin-CreGFP and rough frontal cortical (FC) punches were harvested following a 3-week incubation period. Nuclei were isolated from the PFC tissue and prepared for FACS analysis. Our preparations generated intact neuronal nuclei (Figure 1A C) and we are able to enrich for a subpopulation of GFP-expressing nuclei (Figure 1D, 2A, 2B). Furthermore, RTPCR analysis demonstrated enrichment of GFP mRNA in the GFP-positive nuclei compared to GFP-negative nuclei (Figure 3).

\subsection{Validation of Frontal-cortical loss of Dnmt1 and Dnmt3a in mouse PFC}

To investigate the importance of the principally expressed DNA methyltransferases DNMT1 and DNMT3a in controlling food intake behavior, we used the cre/loxP system to generate conditional deletions in the FC (Figure 4). The Dnmt 1 conditional deletion has exons 4 and 5 contained within the floxed region. The Taqman assay used to measure Dnmt1 mRNA expression spans the exon 5 to exon 6 junctions (Figure 4A). The Dnmt3a conditional deletion has exon 19 contained with the floxed region. The Taqman assay used to measure 
Dnmt3a mRNA expression spans the exon 17 to exon 18 junctions (Figure 4B). We generated FC conditional knockouts of Dnmt1 and Dnmt3a by targeting a viral construct carrying the gene encoding Cre recombinase fused to GFP (AAV2.1-Syn-Cre-GFP) to the PFC of floxed Dnmt1 (Dnmt1 KO), Dnmt3a (Dnmt3a KO), or Dnmt1 and Dnmt3a double (DKO) adult C57bl/6 male mice (Figure 5). Immunostaining of GFP in coronal sections confirmed the expression of Cre recominbase in the FC (Figure 5A). To validate Cre-mediated removal of floxed exons encoding the enzyme active sites of Dnmt1 and Dnmt3a we isolated and examined expression cortical pyramidal neurons. We chose to investigate this genetically defined population of neurons as they present as the principle output pathway from the medial PFC with any changes in cell function resulting from direct or indirect effects of DNMT1 and DNMT3a deletion directly affecting signaling to downstream targets. Comparison of DNMT expression between pyramidal neurons (which express SATB2) that either showed the presence (GFP positive) or absence (GFP negative) of Cre expression revealed a significant decrease in mRNA expression for both Dnmt1 and Dnmt3a (Figures $5 B-C)$.

\subsection{Frontal-cortical loss of Dnmt1 and Dnmt3a selectively suppresses palatable food intake}

In a previous study, we established a food intake paradigm recapitulating hedonic binge-like food intake (Gaykema et al., 2014). Utilizing the same food intake assay, we assessed whether the FC deletion of Dnmt1, Dnmt3a, or both 
methyltransferases altered the animals's drive to consume a highly palatable food. Binge-like feeding on a western diet (WD) having similarly elevated levels of both fat and sucrose was similar to controls for Dnmt1 and Dnmt3a single FC deletions (Dnmt1 SKO Control, $\mathrm{n}=10,0.817 \mathrm{~g} \pm$ 0.043g; Dnmt1 SKO, $\mathrm{n}=12$, $0.774 \mathrm{~g} \pm 0.038 \mathrm{~g} ;$ Dnmt3a SKO Control, $\mathrm{n}=20,0.644 \mathrm{~g} \pm 0.056 \mathrm{~g} ;$ Dnmt3a SKO, $\mathrm{n}=14,0.575 \mathrm{~g} \pm 0.047 \mathrm{~g})$. However, DKO mice consumed significantly less WD than their controls (Control, $n=20,0.644 \mathrm{~g} \pm 0.056 \mathrm{~g}$; DKO, $\mathrm{n}=14,0.427 \pm 0.042 \mathrm{~g}$ ) (Figure 6A). We then repeated the binge-feeding assay with a separate cohort of DKO mice to assess whether suppressed consumption was dependent upon the composition of the palatable food. Using HFD, a diet where the percentage of fat kcal per gram is significantly greater than that of sucrose, we again observed significantly less HFD consumption by DKO mice $(n=12,0.362 g \pm 0.039 g)$ compared to controls $(n=12,0.591 \mathrm{~g} \pm 0.065 \mathrm{~g})$. We then tested whether the suppression of palatable food intake could be maintained following repeated exposure to either WD or HFD. Interestingly, DKO mice showed suppression of intake on HFD only on the first day of binge feeding (Figure 6B). However, DKO mice fed WD showed suppressed binging activity on all three days of testing $(\mathrm{n}=12$, Day1, $0.858 \mathrm{~g} \pm 0.054 \mathrm{~g} ;$ Day2, $0.737 \mathrm{~g} \pm 0.063 \mathrm{~g} ;$ Day3, $0.833 \mathrm{~g} \pm 0.075 \mathrm{~g})$ when compared to controls $(n=12$, Day1, $0.998 \mathrm{~g} \pm 0.040 \mathrm{~g}$; Day2, $0.997 \mathrm{~g} \pm$ 0.059g; Day3, $1.077 \mathrm{~g} \pm 0.065 \mathrm{~g}$ ) on all three days (Figures 6C, 6D). These data suggest that DNMT expression is required to maintain an elevation in palatable food intake and that this elevation is dependent upon the nutrient content of the diet. 
To examine whether the DKO affects food intake of non-palatable rodent chow and thus determine if the effect of DNMT deletion is selective for highly salient palatable food, subjects were individually housed and food consumption of standard chow (TD.7912) was monitored daily for 5 days. DKO and control mice consumed similar amounts of regular chow (Figure 7A, 7B) and maintained similar body weight over 5 days (Figure $7 \mathrm{C}$ ). It is possible that that FC deletion affects feeding behavior only during periods of increased feeding drive resulting from an increase in food salience, independent of nutrient content. We then tested the effect of increasing the salience of their rodent chow by subjecting mice to an $18 \mathrm{hr}$ overnight fast. Chow was then reintroduced and consumption was measured for one hour the following morning. Surprisingly, there was no observable difference in regular chow consumption using the fasting/refeeding paradigm (Figure 7D), suggesting that frontal cortical Dnmt1 and Dnmt3a selectively regulate palatable food intake that is dependent upon nutrient content.

\subsection{FC loss of Dnmts does not affect emotional processing or novelty recognition}

To further describe the role of the DNMT enzymes in regulating palatable food intake, we sought to determine whether FC loss of DNMT1 and DNMT3a contributed to a generalized impairment of affect regulation. In a sucrose preference test, both groups similarly preferred $2 \%$ sucrose over water (Figure 8A), demonstrating that $D n m t 1$ and Dnmt3a deletion was not likely producing anhedonia. Furthermore, DKO mice displayed no differences in both social 
interaction and forced swim behavioral tests when compared to controls (Figures $8 \mathrm{~B}, 8 \mathrm{C})$. To assess whether novelty recognition was playing a part in driving the selective decrease in palatable food consumption, mice underwent a novel object recognition task. No impairment in novel object recognition was observed, with DKO mice spending similar amounts of time interacting with novel objects as control mice (Figure 8D).

Another possibility other than a change in nutrient palatability that could explain the decreased drive to consume palatable food is that Dnmt1 and 3a deletion from the FC results in elevated levels of stress and anxiety. To test whether anxiety levels were increased, subjects were tested for open arm avoidance in an elevated plus maze and center field avoidance using an open field exploration paradigm. DKO were similarly avoidant of open areas as controls (Figures 8E, 8F) and there were no inherent deficiencies in locomotion (Figure 8G). To test if a change in stress reactivity results from Dnmt1 and 3a deletion, we measured serum corticosterone levels at baseline (unstressed) and following acute 30-minute restraint stress. No measurable differences between control and DKO mice (Figure 8H) were observed. Consequently, these data suggest that the selective reduction in palatable food consumption in FC-deleted Dnmt1 and Dnmt3a mice is not due to impairment in affect, novelty recognition or stress reactivity. 


\section{Figures}

Figure 1 - Flow cytometric profile of GFP-positive nuclei
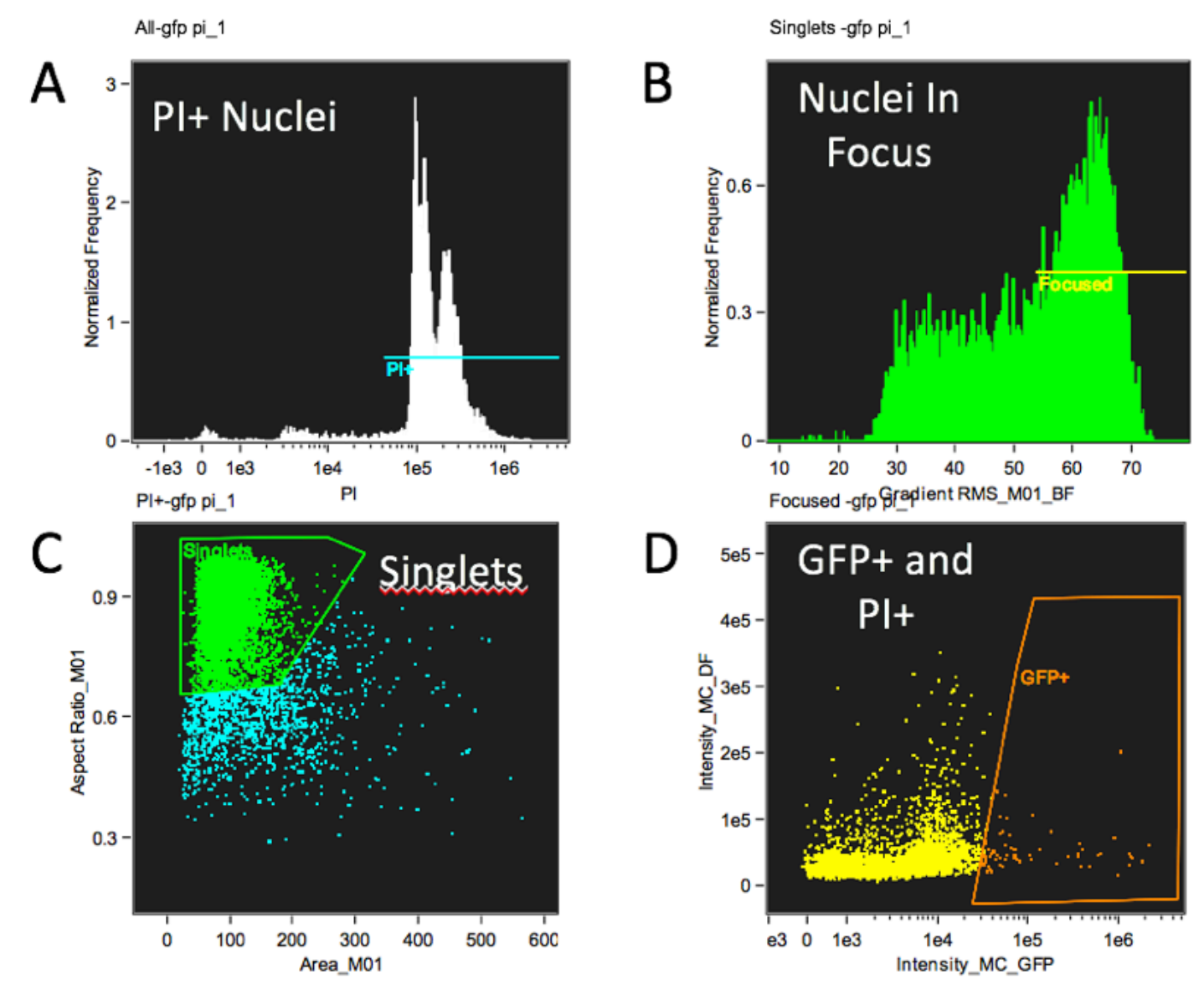

Figure 1. FACS analysis of GFP-positive nuclei. Mice received PFC injections of Synapsin-Cre-GFP and brain tissue was harvest following a 3-week incubation period. Prior to FACS analysis, nuclei were isolated and prepared for FACS analysis. (A-B) Histograms of intact nuclei labelled with PI. (C) Dot plot showing unclustered nuclei. (D) Histogram demonstrating example gating for GFP-postive nuclei 
Figure 2 - Image stream of GFP-positive nuclei GFP+

A

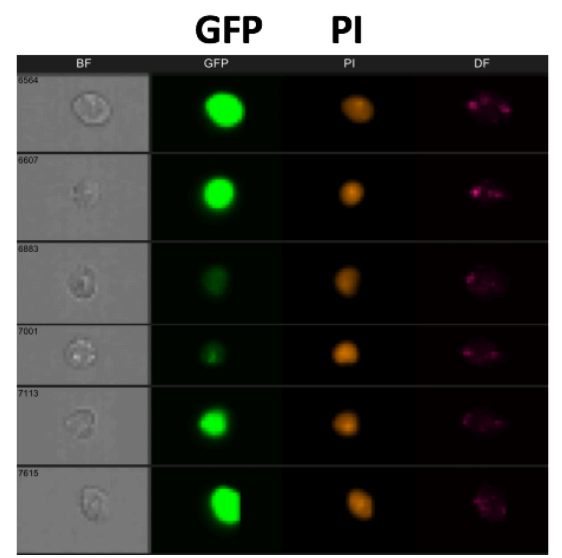

B

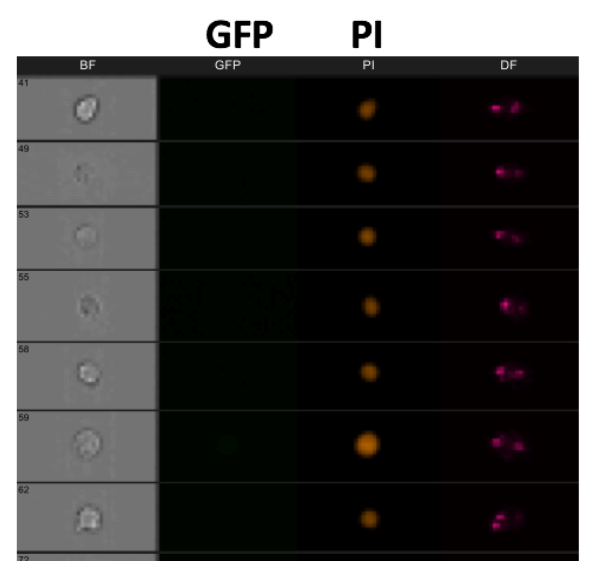

Figure 2. GFP-positive nuclei were analyzed on the Amnis ImageStreamX. Both image stream panels display PI staining, demonstrating intact, healthy nuclei. (A) Demonstration of GFP signal is observed within the GFP+ gated population. (B) Image stream demonstrating nuclei in the GFP-negative gate lack GFP fluorescence. 
Figure 3 - Enrichment of GFP mRNA expression in FACS sorted nuclei

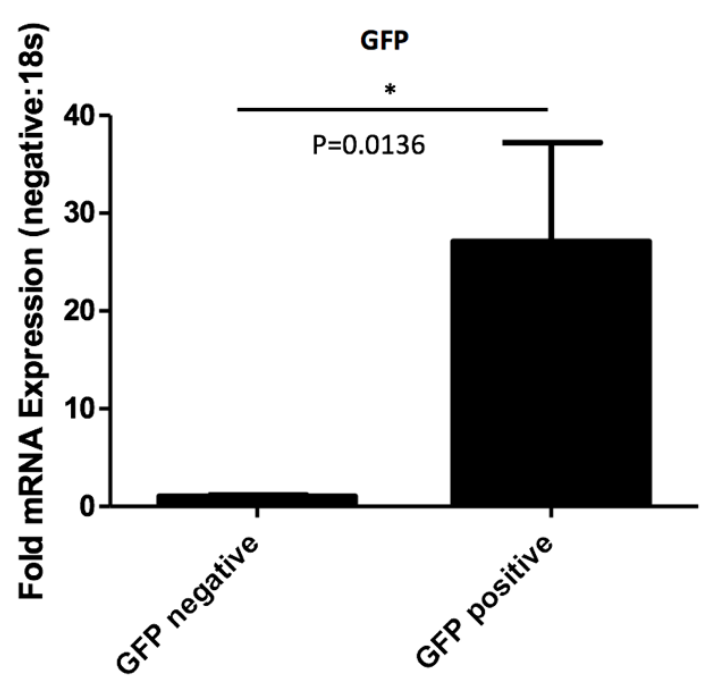

Figure 3. mRNA expression of GFP from FACS sorted nuclei. Mice were injected with Synapsin-Cre-GFP and nuclei were isolated as previously described.

Significant enrichment of GFP mRNA transcripts were measured in the GFPpositive nuclei compared to controls. t-test, $p=0.0136, n=4$. 
Figure 4 - Schematic of Dnmt1 and Dnmt3a conditional alleles

A

Dnmt1

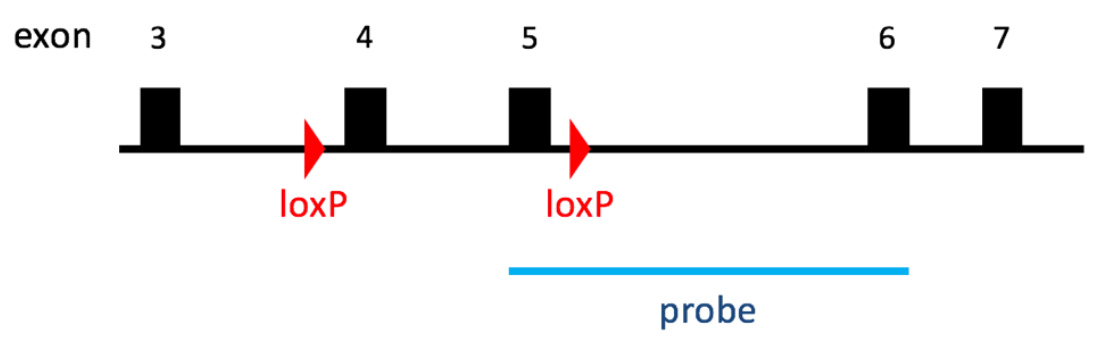

B

\section{Dnmt3a}

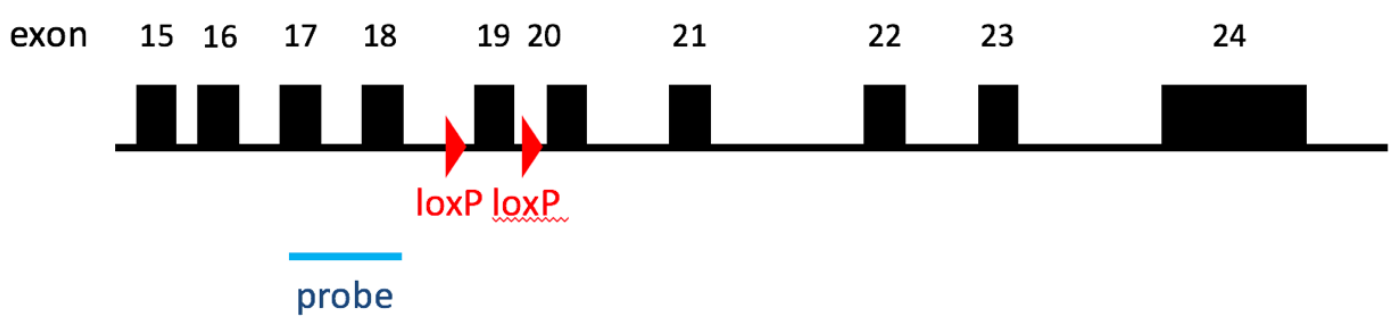

Figure 4. Schematic of Dnmt1 and Dnmt3a conditional alleles with Taqman probe location. (A) The flanking region of the Dnmt 1 conditional allele contains exon 4 and exon 5. The Taqman assay for Dnmt1 spans the exon 5 to exon 6 junctions. (B) The flanking region of the Dnmt3a conditional allele contains exon 19. The Taqman assay for Dnmt3a spans the exon 17 to exon 18 junctions. 
Figure 5 - Frontal-cortical expression of Cre-GFP produces mosaic knockdown of Dnmt1 and Dnmt3a in GFP-positive sorted nuclei

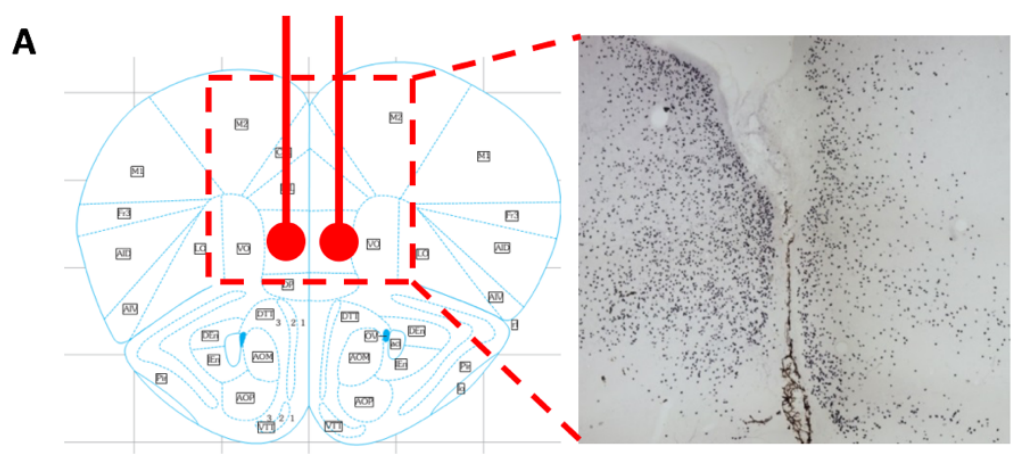

B

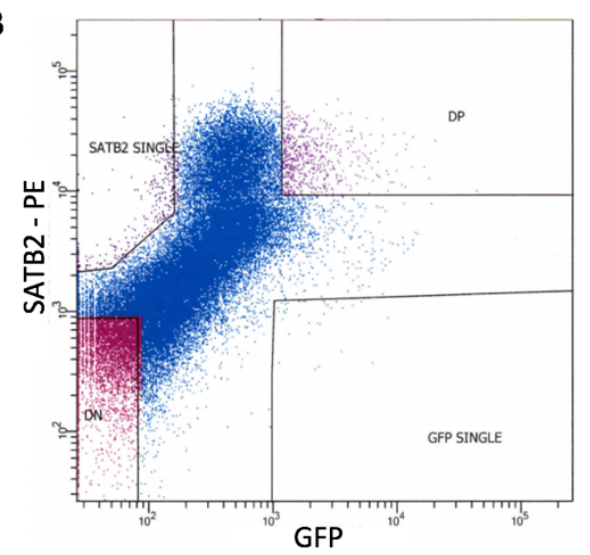

C

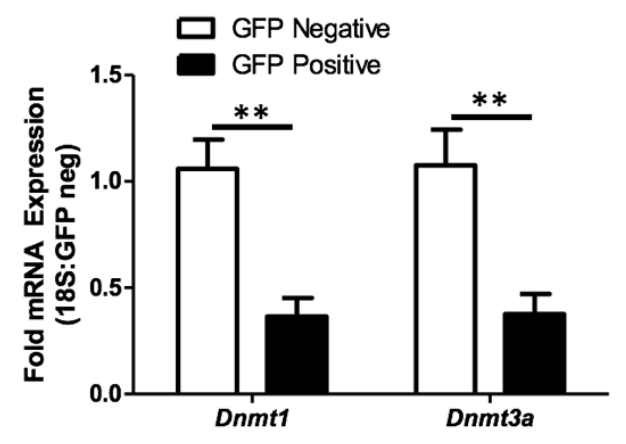

Figure 5. Targeted deletion of both Dnmt1 and Dnmt3a in the mouse prefrontal cortex using AAV-mediated delivery of Cre recombinase. (A) Schematic of coronal slice of the mouse brain (image source: Allen Brain Atlas) showing intended injection site of AAV-Cre-GFP virus (left diagram). Cre-GFP expression is under the control of synapsin and image of GFP-immunostain inset demonstrates viral injection site in the mouse frontal cortex (right image). (B) Plot of FACS-sorted nuclei. Nuclei were sorted and collected with following four criteria: GFP-positive only nuclei, SATB2-positive only nuclei, GFP-positive and SATB2-postive nuclei, and GFP-negative and SATB2-negative nuclei. (C) Summary of fold mRNA expression of Dnmt1 and Dnmt3a in GFP-positive and SATB2 positive nuclei compared to SATB2-only positive. $n=8,{ }^{* *} p<0.01$, twotailed paired $t$ test. 
Figure 6 - Frontal cortical loss of Dnmt1 and Dnmt3a selectively suppresses palatable food intake

A

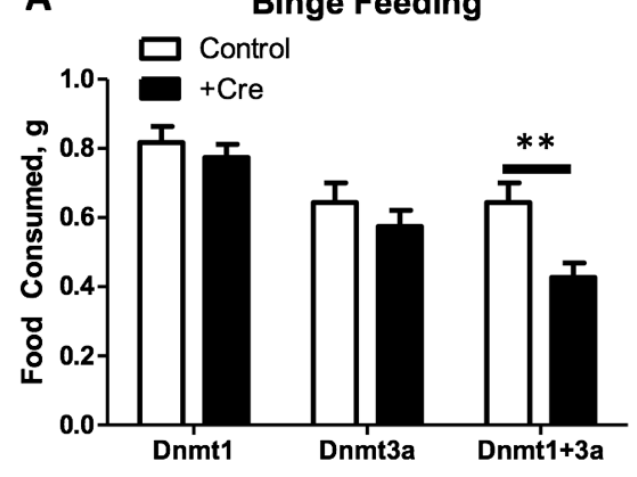

C

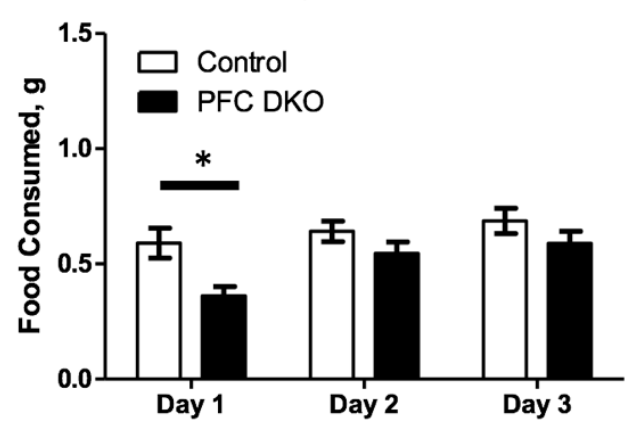

B

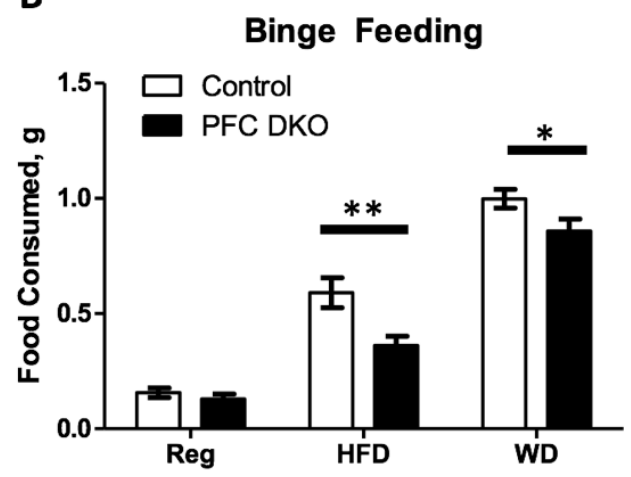

D

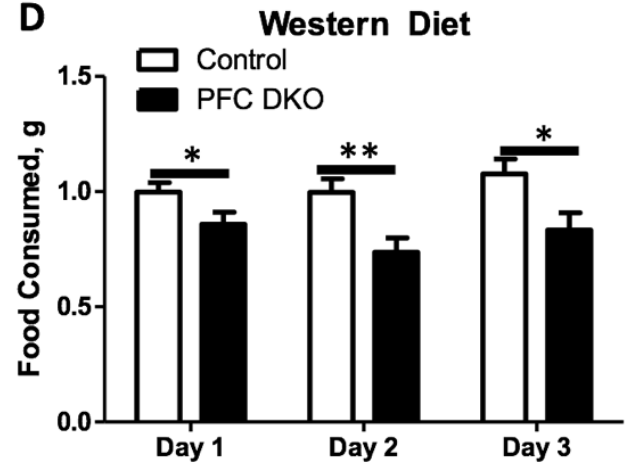

Figure 6. Mice receiving AAV-Cre (DKO) show suppression in binge-like feeding. (A) Mice were fed ad libitum on regular chow. The night prior to testing, mice were presented with a small sample $(0.1-0.25 \mathrm{~g})$ of either a new sample of regular chow or palatable diet. Within 1 hour of lights on, mice were offered a pellet (3$4 \mathrm{~g}$ ) of either a new piece of chow or palatable diet (high fat diet, HFD or western diet, WD) and food consumption was measured for 60 minutes. (A) Deletion of both Dnmt1 and Dnmt3a (DKO) is required to suppress binge-like consumption of western diet. ${ }^{* *} p<0.01$, 2way ANOVA, Post-Hoc Bonferroni multiple comparisons. (B) Dnmt1 and Dnmt3a DKO suppresses binge-feeding of palatable food intake. ${ }^{*} \mathrm{p}<0.05,{ }^{* *} \mathrm{p}<0.01$, $\mathrm{t}$ test for each pair analyzed. (C) Attenuated suppression of binge-like feeding of binge-like feeding of HFD. ${ }^{* *} p<0.01,2$ way ANOVA, Post-Hoc Bonferroni multiple comparisons. (D) Persistent suppression of binge-like feeding on WD. ${ }^{*} p<0.05,{ }^{* *} p<0.01$, 2way ANOVA, Post-Hoc Bonferroni multiple comparisons. 
Figure 7 - Frontal cortical loss of Dnmt1 and Dnmt3a does not alter normal feeding behavior

A

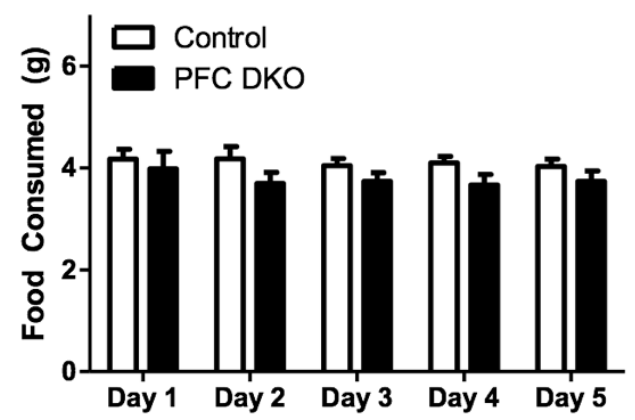

C

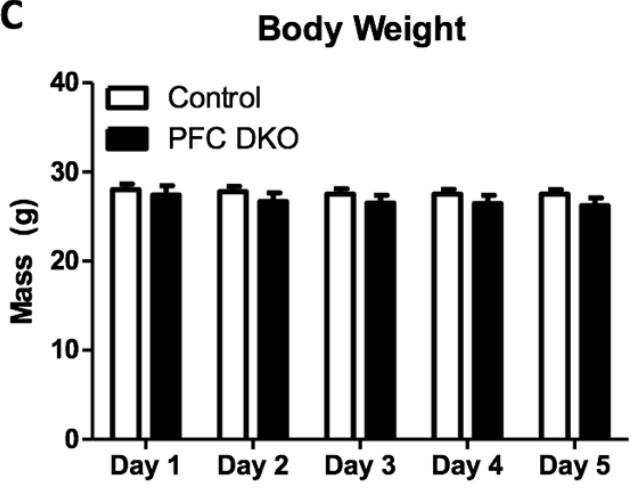

B Cumulative 5-day Food Intake

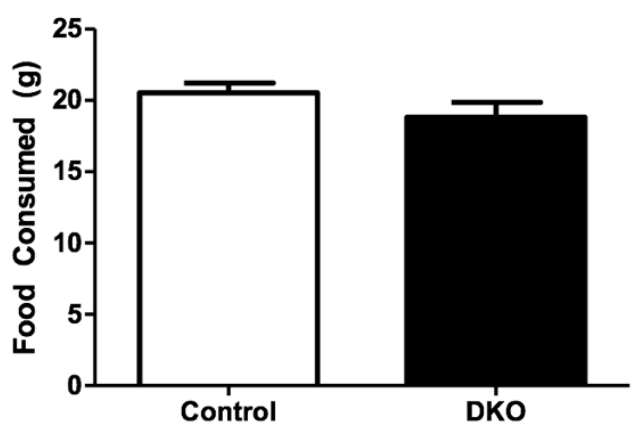

D

Fast/Refeed

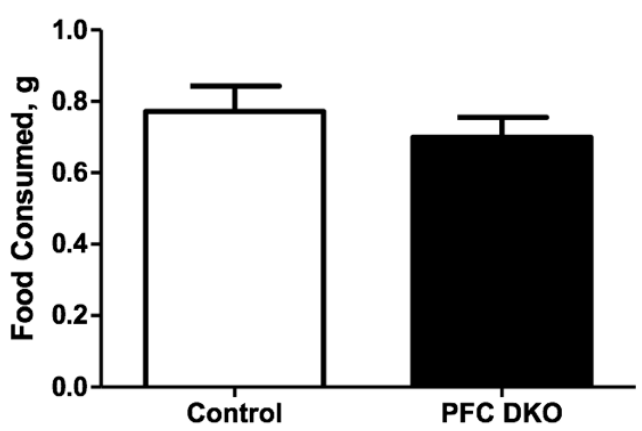

Figure 7. Normal feeding behavior. $(A, B)$ To control for whether the DKO affects overall feeding behavior, subjects were individually housed and food consumption was monitored daily for 5 days. DKO and control mice consume similar levels of regular chow. (C) While monitoring daily food consumption, body weight measurements were also taken. DKO mice have similar body weights compared to controls. (D) DKO and control mice consumed similar amounts of regular chow after an overnight fast. 
Figure 8-FC loss does not affect novelty recognition or affect

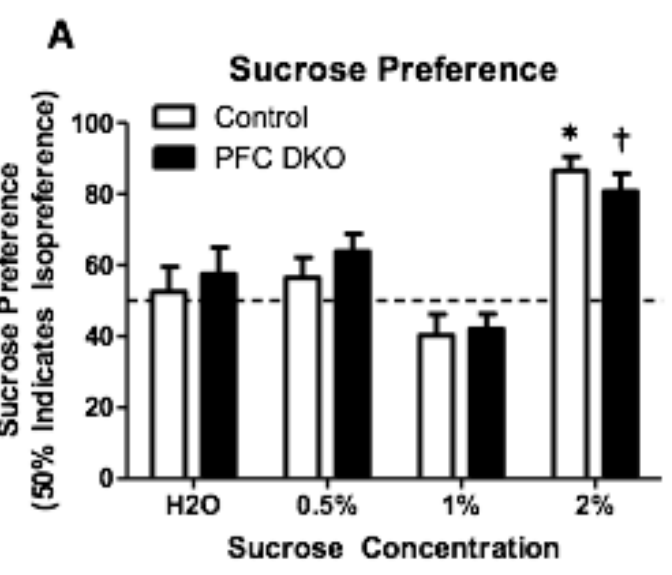

C
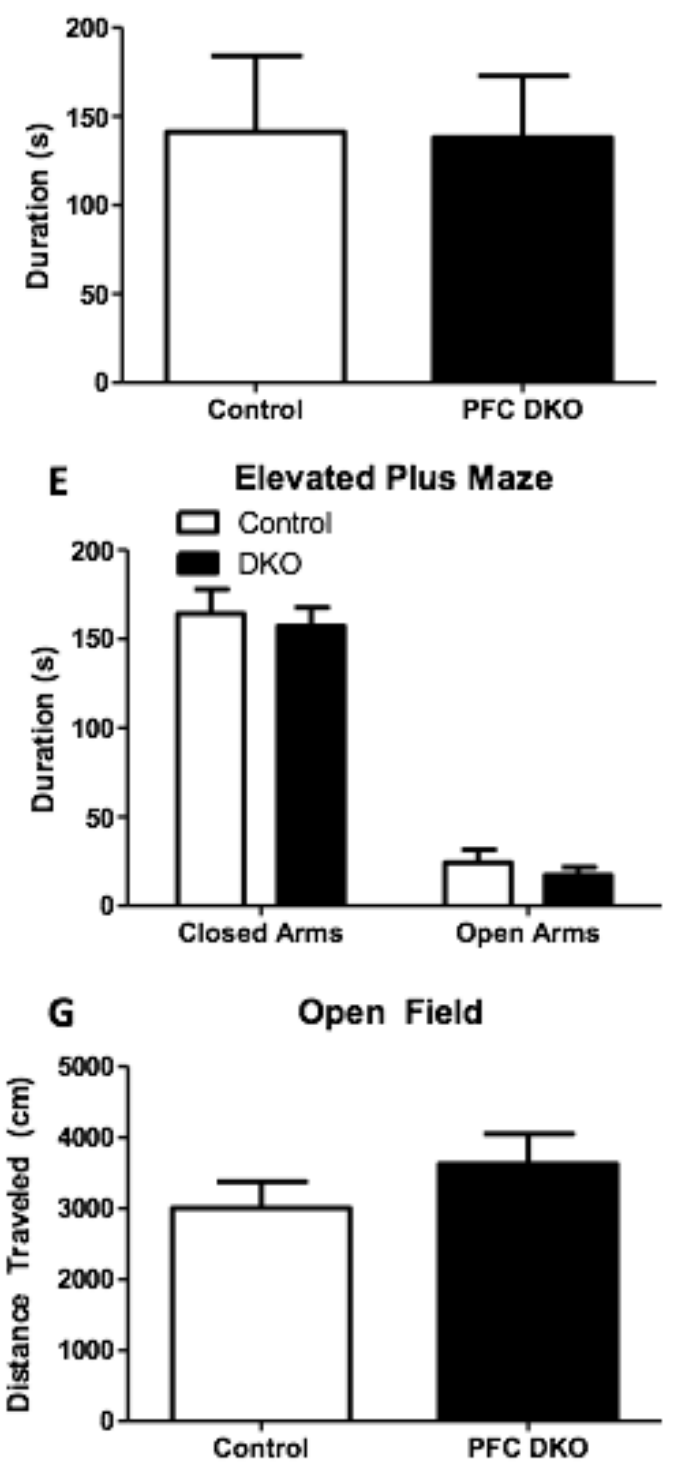
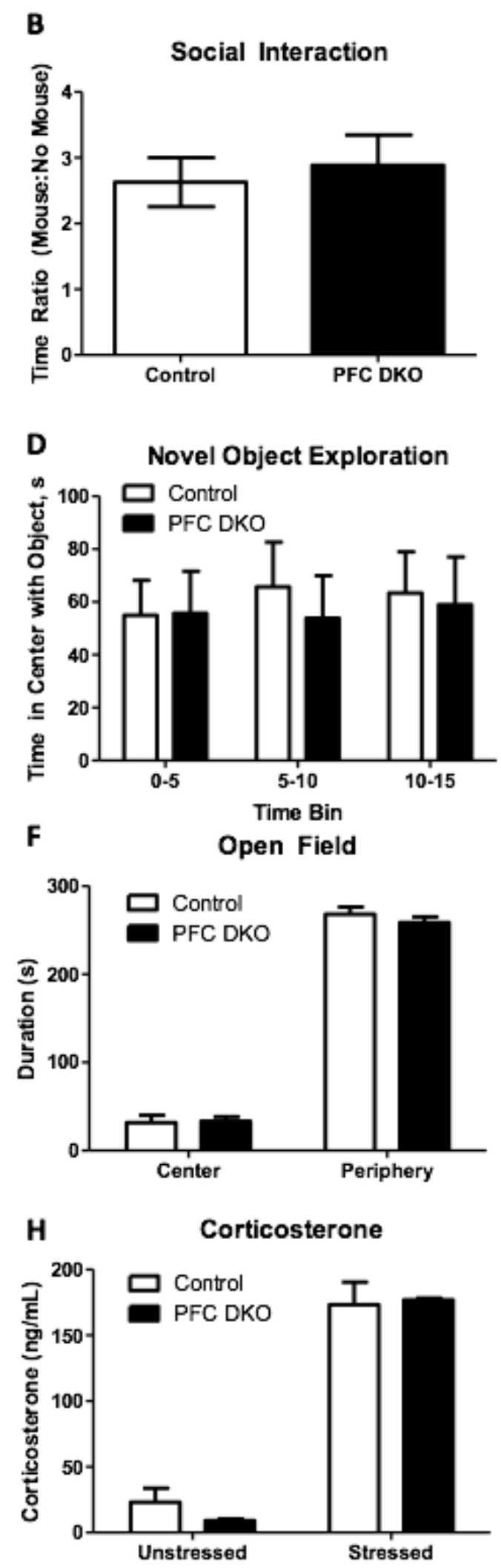
Figure 8. (A) DKO mice show no difference in sucrose preference to controls. ${ }^{* \dagger} p<0.05$, 2way-ANOVA multiple comparisons to no sucrose control. (B) Subjects are allowed to explore a 41 "x41" open square arena with a perforated acrylic cell located in the center of one of the arena walls for 5 minutes (no mouse session). Immediately following the no mouse session, a novel mouse is placed in the perforated cell and subjects are once again allowed to explore the arena. Data is presented as a time ratio of time spent within a zone of interaction with and without the novel mouse. DKO mice show no difference in social interaction compared to controls. (C) DKO mice show no difference in time spent immobile during a forced swim task. (D) DKO mice show no impairment in novelty recognition. (E) DKO mice display no impairment in anxiety expression in an elevated plus maze or $(F)$ open field arena compared to controls. (G) DKO mice do not display any locomotive impairment in an open field arena. (H) FC Dnmt1 and Dnmt3a deletion does not impair HPA function in corticosterone release. 


\section{Discussion and Conclusion}

\subsection{Discussion}

In the current study, we report that loss of the DNA methyltransferases Dnmt1 and Dnmt3a in the frontal cortex (but not the single deletion of Dnmt1 or 3a alone) results in selective reduction of palatable food intake. This result was somewhat surprising, given prior reports that single deletions of the DNMT enzymes can result in behavioral change. Specifically, loss of Dnmt3a alone in the mPFC results in an increase in anxiety like behavior, with Dnmt3a loss from CamKII expressing neurons being sufficient to impair fear dependent learning. Loss of DNMT3a from the accumbens, meanwhile, significantly increases cocaine place preference, in the absence of an effect of DNMT1 deletion. Our work does however agree with a prior report demonstrating the requirement of both DNMT1 and DNMT3a loss to impart behavioral change (Feng et al., 2010). Although DNMT1 and DNMT3a are thought to solely have maintenance and de novo activity respectively, reports have demonstrated overlapping roles. Indeed, DNMT1 can participate in de novo methylation, and DNMT3a can methylate hemimethylated DNA (Kim, Ni, Kelesoglu, Roberts, \& Pradhan, 2002). In our study, we utilized conditional mutants that generate catalytically inactive DNMTs. However, the repressive activity of the DNMTs does not always require their catalytic methyltransferase activity. Several reports have demonstrated that despite deletion of the C-terminal catalytic domain of DNMT1, significant repression of reporter genes have been observed (Kouzarides, Fuks, Burgers, Brehm, \& Hughes-Davies, 2000; Rountree, Bachman, \& Baylin, 2000; Wolffe et 
al., 2000). Intriguingly, it is possible that the DNMTs can serve repressor roles as scaffolding proteins. DNMT1 is known to interact with a number of repressor proteins including the corepressor DMAP1 (Rountree et al., 2000) as well as histone-modifying enzymes, HDAC1/2 (Kouzarides et al., 2000; Wolffe et al., 2000), G9A (Estève et al., 2006), SUV39H1 (Fuks, Hurd, Deplus, \& Kouzarides, 2003), EZH2 (Viré et al., 2005), HP1a, b and g (Smallwood, Estève, Pradhan, \& Carey, 2007), and KDM1A/LSD1 (J. Wang et al., 2009). Indeed, catalytically inactive DNMT can recruit histone modifying enzymes to target gene promoters and repress their expression (Clements et al., 2012). Thus, our work demonstrates the selective neuronal requirement for the methyltransferases in the regulation of feeding behavior, contributing to our understanding of the importance of DNA methylation in the adult animal.

Our data shows that the reduction in food intake with Dnmt1 and Dnmt3a deletion was specific for foods containing both elevated fat and sugar levels (WD) as opposed to diets containing an imbalance in these nutrients (HFD), with no linear relationship between nutrient density and suppression of binge-like food intake observed. In further support of the hypothesized nutrient dependent effect of Dnmt deletion, we observed that DNMT1 and DNMT3a loss did not affect chow intake either in the fed state or in a state where the salience of the chow is elevated following an $18 \mathrm{hr}$ fast. Finally, our conclusion that the Dnmt1 and Dnmt3a knockout reduction in food intake is nutrient dependent is strengthened by our observation in the sucrose preference test that both the DKO and WT animals showed similar consumption of a solution solely composed of sucrose. 
While our work demonstrates a novel, role for the methyltransferases in the cortex, at the same time the data also fit well with studies showing that the prefrontal cortex can modulate nutrient dependent food intake.

This selective effect of DNMT deletion on excessive overeating of palatable food represents the first description of an epigenetic process being responsible for a specific aspect of food intake. While few studies have looked at the consequence of loss of DNMT function on feeding behavior, recent work has shown that DNMT3a when deleted from the paraventricular nucleus of the hypothalamus produces hyperphagia, obesity and glucose intolerance. These results which are opposite of our findings, demonstrate the neuronal and circuit dependent actions of the DNMT enzymes and their resulting effect on genomic methylation. Interestingly, studies in the frontal cortex looking at the effect on single gene methylation changes following excessive intake of palatable food have shown that targets such as the $\mu$-opioid receptor Oprm1 exhibit hypermethylation with the cannabinoid receptor $\mathrm{Cnr1}$ showing demethylation. As both the opioid and cannabinoid receptors have been shown to enhance feeding behavior, these data make it difficult to predict how activity of the DNMT enzymes affect frontal cortical driven food intake. Thus, our data provide significant clarity on the role of the DNMT enzymes in regulating feeding behavior.

Previous studies have also demonstrated that the PFC can regulate an animal's affective state (Covington et al., 2010; Klein et al., 2010; Price \& Drevets, 2012). It has been demonstrated that a negative affective state can 
reduce feeding behavior (Rygula et al., 2005), possibly explaining how Dnmt deletion could be reducing food intake in our experimental system. Surprisingly, our deletion showed remarkable behavioral selectivity, reducing food intake in the absence of an effect on sucrose preference, forced swim activity or social interaction. We also noted that loss of DNMT function did not impact anxiety like behavior or stress responsiveness, physiological processes all modulated by the frontal cortex. The lack of effect on anxiety behavior was especially unanticipated, as recent data has shown that knock down of Dnmt3a alone in the frontal cortex increased anxiety as measured using an elevated plus maze. Our experimental paradigm, however, differed significantly from this prior study, explaining the disparity between the two data sets. For example, while we performed a deletion of the catalytic subunits of the DNMT enzymes, the prior published study of DNMT function in the frontal cortex used an siRNA knockdown strategy to reduce enzyme function. It is possible that non-enzymatic activity of the DNMT protein may remain following our manipulation. Finally, the lack of an observed effect of Dnmt1 and Dnmt3a deletion on stress reactivity was also surprising, as the PFC has been shown to regulate responses to stress by acting as a limbic inhibitory relay to the hypothalamo-pituitary-adrenocortical (HPA) axis (Jones, Myers, \& Herman, 2011; Radley, Gosselink, \& Sawchenko, 2009). We measured no difference in plasma corticosterone when animals were subjected to acute stress, suggesting that frontal cortical deletion of the Dnmts does not affect the hypothalamic-pituitary-adrenal axis function and contribute to any observable heightened stress or anxiety. 
Our observed effect of Dnmt1 and Dnmt3a deletion in the frontal cortex on un-conditioned food intake behavior complements most prior studies that have focused on the role of the methyltransferases on conditional learning. As described above, fear dependent learning, spatial learning and drug-conditioned learning are all affected by the expression of the DNA methyltransferases. Our work shows that, similar to the study by (Kohno et al., 2014) DNMT expression can affect behavior, possibly in the absence of a dependence upon the development of synaptic plasticity. While initial work in DNMT knockout mice showed an impairment in long term potentiation and long term depression in pyramidal neurons, more recent work has also indicated that intrinsic excitability and synaptic scaling may also be increased. It is possible that these same mechanisms drive the selective reduction in food intake observed in the current study. As we performed the Dnmt deletion in both excitatory and inhibitory neurons of the frontal cortex, it is difficult to predict how the activity and output from the prefrontal cortex was altered, although a reduction in food intake suggests a reduction in activity of projections from the cortex that drive feeding behavior. Previously, we described specific activation of disinhibitory interneurons within the mPFC following consumption of a palatable diet suggesting that hedonic consumption of palatable food involves modulating mPFC output (Gaykema et al., 2014). These results in conjunction with the current study support the hypothesis that loss of the Dnmts in the frontal cortex reduces palatable food intake via an overall reduction in MPFC output. It has been demonstrated that a reduction in PFC output can regulate feeding behavior, 
reduce operant responding to sucrose reward, and prevent both drug- and foodinduced reinstatement (Ishikawa, Ambroggi, Nicola, \& Fields, 2008; Land et al., 2014; McFarland \& Kalivas, 2001). One potential mechanism for a reduction in mPFC output is that the areas affected by a hypomethylated DNA state have increased GABAergic tone. Indeed, a reduction in PFC DNA methylation has been associated with increased PFC GABA signaling (Satta et al., 2008b).

We also describe a method that can be used to isolate a discrete population in neurons for subsequent molecular interrogation. It has been demonstrated that the average expression level of a population can be biased by strong expression of just a few (Bengtsson, Ståhlberg, Rorsman, \& Kubista, 2005). In fact, transcript expression levels can vary as much as 1,000 fold between cells that are presumably identical (Raj et al., 2006) suggesting the need to be able to "filter" neurons for detection of potentially more subtle observations. In our case, nuclei expressing Cre recombinase accounted for about $1 \%$ of all nuclei within the tissue and therefore was not possible to measure loss of the DNMT without some form of enrichment. Mature mRNA resides in the nucleus (Weil et al., 2000), and the nuclear and whole cell transcriptomes are similar, with a few noted exceptions including enrichment of transcripts coding for protein families involved in cell cycle, mitosis, and transcription in the nucleus (Grindberg et al., 2013). Taken together, the mRNA harvested from intact neuronal nuclei enriched for DNMT loss by FACS is a valid method to detect loss of DNA methyltransferase expression. 


\subsection{Conclusion}

The work conducted in this dissertation has comprehensively investigated the behavioral relevance of methyltransferase expression in the adult frontal cortex. Additionally, it has generated the ability to selectively interrogate molecular systems in the brain based on neuron cell type. What remains is an investigation of the molecular and circuit level effects of Dnmt1 and Dnmt3a deletion leading to a selective change in food intake awaits further study.

Future work can use Cre viruses to selectively delete the methyltransferases from specific cell populations as opposed all neurons as done in this body of work. Presently, our lab is developing tools to target Cre to somatostatin, a broad class of interneurons. Conceivably, studies conducted in parallel with CamKii-Cre (glutamatergic, excitatory neurons) targeted deletions would provide valuable insight and precision into the modulatory effects of DNA methylation. 


\section{References}

Ahmed, S. H., Kenny, P. J., Koob, G. F., \& Markou, A. (2002). Neurobiological evidence for hedonic allostasis associated with escalating cocaine use. Nature Neuroscience, 5(7), 625. http://doi.org/10.1038/nn872

Avena, N. M., Rada, P., \& Hoebel, B. G. (2008). Evidence for sugar addiction: Behavioral and neurochemical effects of intermittent, excessive sugar intake. Neuroscience \& Biobehavioral Reviews, 32(1), 20-39. http://doi.org/10.1016/j.neubiorev.2007.04.019

Batterham, R. L., Cowley, M. A., Small, C. J., Herzog, H., Cohen, M. A., Dakin, C. L., ... Bloom, S. R. (2002). Gut hormone PYY3-36 physiologically inhibits food intake. Nature, 418(6898), 650-654. http://doi.org/10.1038/nature00887

Bello, N. T., Lucas, L. R., \& Hajnal, A. (2002). Repeated sucrose access influences dopamine D2 receptor density in the striatum. Neuroreport, 13(12), 1575-8. Retrieved from http://www.ncbi.nlm.nih.gov/pubmed/12218708

Bello, N. T., Sweigart, K. L., Lakoski, J. M., Norgren, R., \& Hajnal, A. (2003). Restricted feeding with scheduled sucrose access results in an upregulation of the rat dopamine transporter. American Journal of Physiology Regulatory, Integrative and Comparative Physiology, 284(5).

Bengtsson, M., Ståhlberg, A., Rorsman, P., \& Kubista, M. (2005). Gene expression profiling in single cells from the pancreatic islets of Langerhans reveals lognormal distribution of mRNA levels. Genome Research, 15(10), 1388-92. http://doi.org/10.1101/gr.3820805

Berridge, K. C., \& Kringelbach, M. L. (2008). Affective neuroscience of pleasure: Reward in humans and animals. Psychopharmacology, 199(3), 457-480. http://doi.org/10.1007/s00213-008-1099-6

Bray, G. A., Flatt, J.-P., Volaufova, J., Delany, J. P., \& Champagne, C. M. (2008). Corrective responses in human food intake identified from an analysis of 7-d food-intake records. The American Journal of Clinical Nutrition, 88(6), 150410. http://doi.org/10.3945/ajcn.2008.26289

Brüning, J. C., Gautam, D., Burks, D. J., Gillette, J., Schubert, M., Orban, P. C., ... Kahn, C. R. (2000). Role of Brain Insulin Receptor in Control of Body Weight and Reproduction. Science, 289(5487).

Cassin, S. E., \& von Ranson, K. M. (2007). Is binge eating experienced as an addiction? Appetite (Vol. 49).

Chen, H., Charlat, O., Tartaglia, L. A., Woolf, E. A., Weng, X., Ellis, S. J., ... Morgenstern, J. P. (1996). Evidence That the Diabetes Gene Encodes the Leptin Receptor: Identification of a Mutation in the Leptin Receptor Gene in db/db Mice. Cell, 84(3), 491-495. http://doi.org/10.1016/S00928674(00)81294-5

Chudasama, Y., Passetti, F., Rhodes, S. E. ., Lopian, D., Desai, A., \& Robbins, T. . (2003). Dissociable aspects of performance on the 5-choice serial reaction time task following lesions of the dorsal anterior cingulate, infralimbic and orbitofrontal cortex in the rat: differential effects on selectivity, impulsivity and compulsivity. Behavioural Brain Research, 146(1), 105-119. 
http://doi.org/10.1016/j.bbr.2003.09.020

Citri, A., Pang, Z. P., Südhof, T. C., Wernig, M., \& Malenka, R. C. (2011). Comprehensive qPCR profiling of gene expression in single neuronal cells. Nature Protocols, 7(1), 118-27. http://doi.org/10.1038/nprot.2011.430

Clements, E. G., Mohammad, H. P., Leadem, B. R., Easwaran, H., Cai, Y., Van Neste, L., \& Baylin, S. B. (2012). DNMT1 modulates gene expression without its catalytic activity partially through its interactions with histonemodifying enzymes. Nucleic Acids Research, 40(10), 4334-46. http://doi.org/10.1093/nar/gks031

Considine, R. V., Sinha, M. K., Heiman, M. L., Kriauciunas, A., Stephens, T. W., Nyce, M. R., ... Caro, J. F. (1996). Serum Immunoreactive-Leptin Concentrations in Normal-Weight and Obese Humans. New England Journal of Medicine, 334(5), 292-295.

http://doi.org/10.1056/NEJM199602013340503

Contreras-Rodríguez, O., Martín-Pérez, C., Vilar-López, R., \& Verdejo-Garcia, A. (2015). Ventral and Dorsal Striatum Networks in Obesity: Link to Food Craving and Weight Gain. Biological Psychiatry. http://doi.org/10.1016/j.biopsych.2015.11.020

Covington, H. E., Lobo, M. K., Maze, I., Vialou, V., Hyman, J. M., Zaman, S., ... Nestler, E. J. (2010). Antidepressant effect of optogenetic stimulation of the medial prefrontal cortex. The Journal of Neuroscience: The Official Journal of the Society for Neuroscience, 30(48), 16082-16090. http://doi.org/10.1523/JNEUROSCI.1731-10.2010

Cowley, M. A., Smart, J. L., Rubinstein, M., Cerdán, M. G., Diano, S., Horvath, T. L., ... Low, M. J. (2001). Leptin activates anorexigenic POMC neurons through a neural network in the arcuate nucleus. Nature, 411(6836), 480484. http://doi.org/10.1038/35078085

Day, J. J., Childs, D., Guzman-Karlsson, M. C., Kibe, M., Moulden, J., Song, E., ... Sweatt, J. D. (2013). DNA methylation regulates associative reward learning. Nature Neuroscience, 16(10), 1445-52. http://doi.org/10.1038/nn.3504

Dodge, J. E., Okano, M., Dick, F., Tsujimoto, N., Chen, T., Wang, S., ... Li, E. (2005). Inactivation of Dnmt3b in mouse embryonic fibroblasts results in DNA hypomethylation, chromosomal instability, and spontaneous immortalization. The Journal of Biological Chemistry, 280(18), 17986-17991. http://doi.org/10.1074/jbc.M413246200

Elmquist, J. K., Elias, C. F., \& Saper, C. B. (1999). From Lesions to Leptin: Hypothalamic Control of Food Intake and Body Weight. Neuron, 22(2), 221232. http://doi.org/10.1016/S0896-6273(00)81084-3

Estève, P.-O., Chin, H. G., Smallwood, A., Feehery, G. R., Gangisetty, O., Karpf, A. R., ... Pradhan, S. (2006). Direct interaction between DNMT1 and G9a coordinates DNA and histone methylation during replication. Genes \& Development, 20(22), 3089-103. http://doi.org/10.1101/gad.1463706

Fan, G., Beard, C., Chen, R. Z., Csankovszki, G., Sun, Y., Siniaia, M., ... Jaenisch, R. (2001). DNA hypomethylation perturbs the function and survival of CNS neurons in postnatal animals. The Journal of Neuroscience : The 
Official Journal of the Society for Neuroscience, 21(3), 788-797.

Feng, J., Chang, H., Li, E., \& Fan, G. (2005). Dynamic expression of de novo DNA methyltransferases Dnmt3a and Dnmt3b in the central nervous system. Journal of Neuroscience Research, 79(6), 734-746. http://doi.org/10.1002/jnr.20404

Feng, J., Zhou, Y., Campbell, S. L., Le, T., Li, E., Sweatt, J. D., ... Fan, G. (2010). Dnmt1 and Dnmt3a maintain DNA methylation and regulate synaptic function in adult forebrain neurons. Nature Neuroscience, 13(4), 423-30. http://doi.org/10.1038/nn.2514

Finkelstein, E. A., Trogdon, J. G., Cohen, J. W., \& Dietz, W. (2009). Annual medical spending attributable to obesity: payer-and service-specific estimates. Health Affairs (Project Hope), 28(5), w822-31. http://doi.org/10.1377/hlthaff.28.5.w822

Flegal, K. M., Carroll, M. D., Kit, B. K., Ogden, C. L., A, B., P, B., ... B, R. (2012). Prevalence of Obesity and Trends in the Distribution of Body Mass Index Among US Adults, 1999-2010. JAMA, 307(5), 491. http://doi.org/10.1001/jama.2012.39

Frick, K. M., \& Gresack, J. E. (2003). Sex differences in the behavioral response to spatial and object novelty in adult C57BL/6 mice. Behavioral Neuroscience, 117(6), 1283-91. http://doi.org/10.1037/07357044.117.6.1283

Fuks, F., Hurd, P. J., Deplus, R., \& Kouzarides, T. (2003). The DNA methyltransferases associate with HP1 and the SUV39H1 histone methyltransferase. Nucleic Acids Research, 31(9), 2305-12. Retrieved from http://www.ncbi.nlm.nih.gov/pubmed/12711675

Gabbott, P. L. a, Warner, T. a., Jays, P. R. L., Salway, P., \& Busby, S. J. (2005). Prefrontal cortex in the rat: Projections to subcortical autonomic, motor, and limbic centers. Journal of Comparative Neurology, 492(2), 145-177. http://doi.org/10.1002/cne.20738

Gálosi, R., Hajnal, A., Petykó, Z., Hartmann, G., Karádi, Z., \& Lénárd, L. (2015). The role of catecholamine innervation in the medial prefrontal cortex on the regulation of body weight and food intake. Behavioural Brain Research, 286, 318-327. http://doi.org/10.1016/j.bbr.2015.03.017

Gardiner-Garden, M., \& Frommer, M. (1987). CpG Islands in vertebrate genomes. Journal of Molecular Biology, 196(2), 261-282. http://doi.org/10.1016/0022-2836(87)90689-9

Gaykema, R. P. A., Nguyen, X.-M. T., Boehret, J. M., Lambeth, P. S., Joy-Gaba, J., Warthen, D. M., \& Scott, M. M. (2014). Characterization of excitatory and inhibitory neuron activation in the mouse medial prefrontal cortex following palatable food ingestion and food driven exploratory behavior. Frontiers in Neuroanatomy, 8, 60. http://doi.org/10.3389/fnana.2014.00060

Gibbs, J., Young, R. C., \& Smith, G. P. (1997). Cholecystokinin Decreases Food Intake in Rats ${ }^{1}$. Obesity Research, 5(3), 284-290. http://doi.org/10.1002/j.1550-8528.1997.tb00305.x

Golshani, P., Hutnick, L., Schweizer, F., \& Fan, G. (2005). Conditional Dnmt1 deletion in dorsal forebrain disrupts development of somatosensory barrel 
cortex and thalamocortical long-term potentiation. Thalamus \& Related Systems, 3(3), 227-233. http://doi.org/10.1017/S1472928807000222

Grill, H. J., \& Kaplan, J. M. (2002). The Neuroanatomical Axis for Control of Energy Balance. Frontiers in Neuroendocrinology, 23(1), 2-40. http://doi.org/10.1006/frne.2001.0224

Grindberg, R. V, Yee-Greenbaum, J. L., McConnell, M. J., Novotny, M., O'Shaughnessy, A. L., Lambert, G. M., ... Lasken, R. S. (2013). RNAsequencing from single nuclei. Proceedings of the National Academy of Sciences of the United States of America, 110(49), 19802-7. http://doi.org/10.1073/pnas.1319700110

Heni, M., Kullmann, S., Veit, R., Ketterer, C., Frank, S., Machicao, F., ... Fritsche, A. (2014). Variation in the obesity risk gene FTO determines the postprandial cerebral processing of food stimuli in the prefrontal cortex. Molecular Metabolism, 3(2), 109-113. http://doi.org/10.1016/j.molmet.2013.11.009

Hoebel, B. G., \& Teitelbaum, P. (1962). Hypothalamic Control of Feeding and Self-Stimulation. Science, 135(3501).

Holliday, R., \& Pugh, J. E. (1975). DNA modification mechanisms and gene activity during development. Science, 187(4173), 226 LP-232. JOUR. Retrieved from http://science.sciencemag.org/content/187/4173/226.abstract

Huang, H.-L., Hsing, H.-W., Lai, T.-C., Chen, Y.-W., Lee, T.-R., Chan, H.-T., ... Chan, H.-L. (2010). Trypsin-induced proteome alteration during cell subculture in mammalian cells. Journal of Biomedical Science, 17(1), 36. http://doi.org/10.1186/1423-0127-17-36

Huang, Y., Song, N.-N., Lan, W., Hu, L., Su, C.-J., Ding, Y.-Q., \& Zhang, L. (2013). Expression of Transcription Factor Satb2 in Adult Mouse Brain. The Anatomical Record, 296(3), 452-461. http://doi.org/10.1002/ar.22656

Hutnick, L. K., Golshani, P., Namihira, M., Xue, Z., Matynia, A., Yang, X. W., ... Fan, G. (2009). DNA hypomethylation restricted to the murine forebrain induces cortical degeneration and impairs postnatal neuronal maturation. Human Molecular Genetics, 18(15), 2875-88. http://doi.org/10.1093/hmg/ddp222

Ikeda, M., Brown, J., Holland, A. J., Fukuhara, R., \& Hodges, J. R. (2002). Changes in appetite, food preference, and eating habits in frontotemporal dementia and Alzheimer's disease. Journal of Neurology, Neurosurgery, and Psychiatry, 73(4), 371-6. http://doi.org/10.1136/JNNP.73.4.371

Inano, K., Suetake, I., Ueda, T., Miyake, Y., Nakamura, M., Okada, M., \& Tajima, S. (2000). Maintenance-type DNA methyltransferase is highly expressed in post-mitotic neurons and localized in the cytoplasmic compartment. Journal of Biochemistry, 128(2), 315-321.

Ingalls, A. M., Dickie, M. M., \& Snell, G. D. (1950). OBESE, A NEW MUTATION IN THE HOUSE MOUSE. Journal of Heredity, 41(12), 317-318. JOUR. Retrieved from http://jhered.oxfordjournals.org/content/41/12/317.short Ishikawa, A., Ambroggi, F., Nicola, S. M., \& Fields, H. L. (2008). Dorsomedial prefrontal cortex contribution to behavioral and nucleus accumbens neuronal responses to incentive cues. The Journal of Neuroscience: The Official 
Journal of the Society for Neuroscience, 28(19), 5088-98.

http://doi.org/10.1523/JNEUROSCI.0253-08.2008

Jaenisch, R., Jackson-Grusby, L., Beard, C., Possemato, R., Tudor, M., Fambrough, D., ... Lander, E. (2001). Loss of genomic methylation causes p53-dependent apoptosis and epigeneticderegulation. Nature Genetics, 27(1), 31-39. http://doi.org/10.1038/83730

Johnson, P. M., \& Kenny, P. J. (2010). Dopamine D2 receptors in addiction-like reward dysfunction and compulsive eating in obese rats. Nature Neuroscience, 13(5), 635-641. http://doi.org/10.1038/nn.2519

Jones, K. R., Myers, B., \& Herman, J. P. (2011). Stimulation of the prelimbic cortex differentially modulates neuroendocrine responses to psychogenic and systemic stressors. Physiology and Behavior, 104(2), 266-271. http://doi.org/10.1016/j.physbeh.2011.03.021

Jüttermann, R., Li, E., \& Jaenisch, R. (1994). Toxicity of 5-aza-2'-deoxycytidine to mammalian cells is mediated primarily by covalent trapping of DNA methyltransferase rather than DNA demethylation. Proceedings of the National Academy of Sciences of the United States of America, 91(25), 11797-801. Retrieved from http://www.ncbi.nlm.nih.gov/pubmed/7527544

Killgore, W. D. ., Young, A. D., Femia, L. A., Bogorodzki, P., Rogowska, J., \& Yurgelun-Todd, D. A. (2003). Cortical and limbic activation during viewing of high- versus low-calorie foods. Neurolmage, 19(4), 1381-1394. http://doi.org/10.1016/S1053-8119(03)00191-5

Kim, G.-D., Ni, J., Kelesoglu, N., Roberts, R. J., \& Pradhan, S. (2002). Cooperation and communication between the human maintenance and de novo DNA (cytosine-5) methyltransferases. The EMBO Journal, 21(15), 4183-95. http://doi.org/10.1093/emboj/cdf401

Kita, H., \& Kitai, S. T. (1990). Amygdaloid projections to the frontal cortex and the striatum in the rat. The Journal of Comparative Neurology, 298(1), 40-49. http://doi.org/10.1002/cne.902980104

Klein, J., Winter, C., Coquery, N., Heinz, A., Morgenstern, R., Kupsch, A., \& Juckel, G. (2010). Lesion of the medial prefrontal cortex and the subthalamic nucleus selectively affect depression-like behavior in rats. Behavioural Brain Research, 213(1), 73-81. http://doi.org/10.1016/j.bbr.2010.04.036

Kohno, D., Lee, S., Harper, M. J., Kim, K. W., Sone, H., Sasaki, T., ... Elmquist, J. K. (2014). Dnmt3a in Sim1 neurons is necessary for normal energy homeostasis. The Journal of Neuroscience: The Official Journal of the Society for Neuroscience, 34(46), 15288-96. http://doi.org/10.1523/JNEUROSCI.1316-14.2014

Koob, G. F., \& Le Moal, M. (2005). Plasticity of reward neurocircuitry and the "dark side" of drug addiction. Nature Neuroscience, 8(11), 1442-1444. http://doi.org/10.1038/nn1105-1442

Koob, G. F., \& Le Moal, M. (2008). Addiction and the Brain Antireward System. Annual Review of Psychology, 59(1), 29-53. http://doi.org/10.1146/annurev.psych.59.103006.093548

Kouzarides, T., Fuks, F., Burgers, W. A., Brehm, A., \& Hughes-Davies, L. (2000). DNA methyltransferase Dnmt1 associates with histone deacetylase activity. 
Nature Genetics, 24(1), 88-91. http://doi.org/10.1038/71750

Land, B. B., Narayanan, N. S., Liu, R.-J., Gianessi, C. A., Brayton, C. E., Grimaldi, D. M., ... DiLeone, R. J. (2014). Medial prefrontal D1 dopamine neurons control food intake. Nature Neuroscience, 17(2), 248-53. http://doi.org/10.1038/nn.3625

Landtblom, A.-M., Dige, N., Schwerdt, K., Safstrom, P., \& Granerus, G. (2002). A case of Kleine-Levin syndrome examined with SPECT and neuropsychological testing. Acta Neurologica Scandinavica, 105(4), 318321. http://doi.org/10.1034/j.1600-0404.2002.1c162.x

Lavagnino, L., Arnone, D., Cao, B., Soares, J. C., \& Selvaraj, S. (2016). Inhibitory control in obesity and binge eating disorder: A systematic review and metaanalysis of neurocognitive and neuroimaging studies. Neuroscience \& Biobehavioral Reviews, 68, 714-726. http://doi.org/10.1016/j.neubiorev.2016.06.041

Lein, E. S., Hawrylycz, M. J., Ao, N., Ayres, M., Bensinger, A., Bernard, A., ... Jones, A. R. (2007). Genome-wide atlas of gene expression in the adult mouse brain. Nature, 445(7124), 168-176. http://doi.org/10.1038/nature05453

Leinninger, G. M., Jo, Y.-H., Leshan, R. L., Louis, G. W., Yang, H., Barrera, J. G., ... Jr. (2009). Leptin acts via leptin receptor-expressing lateral hypothalamic neurons to modulate the mesolimbic dopamine system and suppress feeding. Cell Metabolism, 10(2), 89-98. http://doi.org/10.1016/j.cmet.2009.06.011

Leinninger, G. M., \& Myers, M. G. (2007). LRb signals act within a distributed network of leptin-responsive neurones to mediate leptin action. Acta Physiologica, 192(1), 49-59. http://doi.org/10.1111/j.17481716.2007.01784.x

Levenson, J. M., Roth, T. L., Lubin, F. D., Miller, C. a, Huang, I.-C., Desai, P., ... Sweatt, J. D. (2006). Evidence that DNA (cytosine-5) methyltransferase regulates synaptic plasticity in the hippocampus. The Journal of Biological Chemistry, 281(23), 15763-15773. http://doi.org/10.1074/jbc.M511767200

Li, E., Bestor, T. H., \& Jaenisch, R. (1992). Targeted mutation of the DNA methyltransferase gene results in embryonic lethality. Cell, 69(6), 915-926. http://doi.org/10.1016/0092-8674(92)90611-F

Lovatt, D., Bell, T., \& Eberwine, J. (2015). Single-neuron isolation for RNA analysis using pipette capture and laser capture microdissection. Cold Spring Harbor Protocols, 2015(1), pdb.prot072439. http://doi.org/10.1101/pdb.prot072439

Lovatt, D., Ruble, B. K., Lee, J., Dueck, H., Kim, T. K., Fisher, S., ... Eberwine, J. (2014). Transcriptome in vivo analysis (TIVA) of spatially defined single cells in live tissue. Nature Methods, 11(2), 190-196. http://doi.org/10.1038/nmeth.2804

Lubin, F. D., Roth, T. L., \& Sweatt, J. D. (2008). Epigenetic regulation of BDNF gene transcription in the consolidation of fear memory. The Journal of Neuroscience: The Official Journal of the Society for Neuroscience, 28(42), 10576-86. http://doi.org/10.1523/JNEUROSCI.1786-08.2008 
Maddox, S. A., \& Schafe, G. E. (2011). Epigenetic alterations in the lateral amygdala are required for reconsolidation of a Pavlovian fear memory. Learning \& Memory (Cold Spring Harbor, N.Y.), 18(9), 579-93. http://doi.org/10.1101//m.2243411

Marsh, R., Steinglass, J. E., Gerber, A. J., Graziano O'Leary, K., Wang, Z., Murphy, D., ... JC, D. (2009). Deficient Activity in the Neural Systems That Mediate Self-regulatory Control in Bulimia Nervosa. Archives of General Psychiatry, 66(1), 51. http://doi.org/10.1001/archgenpsychiatry.2008.504

McFarland, K., \& Kalivas, P. W. (2001). The Circuitry Mediating Cocaine-Induced Reinstatement of Drug-Seeking Behavior. J. Neurosci., 21(21), 8655-8663. Retrieved from http://www.jneurosci.org/content/21/21/8655

Meadows, J. P., Guzman-Karlsson, M. C., Phillips, S., Brown, J. A., Strange, S. K., Sweatt, J. D., \& Hablitz, J. J. (2016). Dynamic DNA methylation regulates neuronal intrinsic membrane excitability. Science Signaling, 9(442).

Meadows, J. P., Guzman-Karlsson, M. C., Phillips, S., Holleman, C., Posey, J. L., Day, J. J., ... Pfaffl, M. W. (2015). DNA methylation regulates neuronal glutamatergic synaptic scaling. Science Signaling, 8(382), ra61. http://doi.org/10.1126/scisignal.aab0715

Mena, J. D., Sadeghian, K., \& Baldo, B. A. (2011). Induction of hyperphagia and carbohydrate intake by $\mu$-opioid receptor stimulation in circumscribed regions of frontal cortex. The Journal of Neuroscience : The Official Journal of the Society for Neuroscience, 31(9), 3249-60. http://doi.org/10.1523/JNEUROSCI.2050-10.2011

Miller, C. a, \& Sweatt, J. D. (2007). Covalent modification of DNA regulates memory formation. Neuron, 53(6), 857-69. http://doi.org/10.1016/j.neuron.2007.02.022

Molyneaux, B. J., Arlotta, P., Menezes, J. R. L., \& Macklis, J. D. (2007). Neuronal subtype specification in the cerebral cortex. Nature Reviews Neuroscience, 8(6), 427-437. http://doi.org/10.1038/nrn2151

Morton, G. J., Meek, T. H., \& Schwartz, M. W. (2014). Neurobiology of food intake in health and disease. Nature Reviews Neuroscience, 15(6), 367378. http://doi.org/10.1038/nrn3745

Nguyen, S., Meletis, K., Fu, D., Jhaveri, S., \& Jaenisch, R. (2007). Ablation of de novo DNA methyltransferase Dnmt3a in the nervous system leads to neuromuscular defects and shortened lifespan. Developmental Dynamics, 236(6), 1663-1676. http://doi.org/10.1002/dvdy.21176

Okano, M., Bell, D. W., Haber, D. A., \& Li, E. (1999). DNA Methyltransferases Dnmt3a and Dnmt3b Are Essential for De Novo Methylation and Mammalian Development. Cell, 99(3), 247-257. http://doi.org/10.1016/S00928674(00)81656-6

Price, J. L., \& Drevets, W. C. (2012). Neural circuits underlying the pathophysiology of mood disorders. Trends in Cognitive Sciences, 16(1), 61-71. http://doi.org/10.1016/j.tics.2011.12.011

Radley, J. J., Gosselink, K. L., \& Sawchenko, P. E. (2009). NIH Public Access, 29(22), 7330-7340. http://doi.org/10.1523/JNEUROSCI.5924-08.2009.A

Raj, A., Peskin, C. S., Tranchina, D., Vargas, D. Y., Tyagi, S., Becskei, A., ... 
Singer, R. (2006). Stochastic mRNA Synthesis in Mammalian Cells. PLoS Biology, 4(10), e309. http://doi.org/10.1371/journal.pbio.0040309

Regard, M., \& Landis, T. (1997). \&quot;Gourmand syndrome\&quot;:: eating passion associated with right anterior lesions. Neurology, 48(5), 1185-90. http://doi.org/10.1212/WNL.48.5.1185

Risold, P. ., Thompson, R. ., \& Swanson, L. . (1997). The structural organization of connections between hypothalamus and cerebral cortex. Brain Research Reviews, 24(2), 197-254. http://doi.org/10.1016/S0165-0173(97)00007-6

Rolls, B. J., \& Bell, E. A. (1999). Intake of fat and carbohydrate: role of energy density. European Journal of Clinical Nutrition, 53(s1), s166-s173. http://doi.org/10.1038/sj.ejcn.1600757

Rountree, M. R., Bachman, K. E., \& Baylin, S. B. (2000). DNMT1 binds HDAC2 and a new co-repressor, DMAP1, to form a complex atreplication foci. Nature Genetics, 25(3), 269-277. http://doi.org/10.1038/77023

Russo, S. J., Dietz, D. M., Dumitriu, D., Morrison, J. H., Malenka, R. C., \& Nestler, E. J. (2010). The addicted synapse: mechanisms of synaptic and structural plasticity in nucleus accumbens. Trends in Neurosciences, 33(6), 267-276. http://doi.org/10.1016/j.tins.2010.02.002

Rygula, R., Abumaria, N., Flügge, G., Fuchs, E., Rüther, E., \& HavemannReinecke, U. (2005). Anhedonia and motivational deficits in rats: impact of chronic social stress. Behavioural Brain Research, 162(1), 127-34. http://doi.org/10.1016/j.bbr.2005.03.009

Satoh, N., Ogawa, Y., Katsuura, G., Hayase, M., Tsuji, T., Imagawa, K., ... Nakao, K. (1997). The arcuate nucleus as a primary site of satiety effect of leptin in rats. Neuroscience Letters, 224(3), 149-152.

http://doi.org/10.1016/S0304-3940(97)00163-8

Satta, R., Maloku, E., Zhubi, a, Pibiri, F., Hajos, M., Costa, E., \& Guidotti, a. (2008a). Nicotine decreases DNA methyltransferase 1 expression and glutamic acid decarboxylase 67 promoter methylation in GABAergic interneurons. Proceedings of the National Academy of Sciences of the United States of America, 105(42), 16356-61. http://doi.org/10.1073/pnas.0808699105

Satta, R., Maloku, E., Zhubi, a, Pibiri, F., Hajos, M., Costa, E., \& Guidotti, a. (2008b). Nicotine decreases DNA methyltransferase 1 expression and glutamic acid decarboxylase 67 promoter methylation in GABAergic interneurons. Proceedings of the National Academy of Sciences of the United States of America, 105(42), 16356-16361.

Schultz, W. (2007). Behavioral dopamine signals. Trends in Neurosciences, 30(5), 203-210. http://doi.org/10.1016/j.tins.2007.03.007

Schwartz, M. W., Hahn, T. M., Breininger, J. F., \& Baskin, D. G. (1998). Coexpression of Agrp and NPY in fasting-activated hypothalamic neurons. Nature Neuroscience, 1(4), 271-272. http://doi.org/10.1038/1082

Schwartz, M. W., Woods, S. C., Porte, D., Seeley, R. J., \& Baskin, D. G. (2000). Central nervous system control of food intake. Nature, Published Online: 06 April 2000; | doi:10.1038/35007534, 404(6778), 661. http://doi.org/10.1038/35007534 
Shi, C.-J., \& Cassell, M. D. (1998). Cortical, thalamic, and amygdaloid connections of the anterior and posterior insular cortices. The Journal of Comparative Neurology, 399(4), 440-468. http://doi.org/10.1002/(SICI)10969861(19981005)399:4<440::AID-CNE2>3.0.CO;2-1

Small, D. M., Veldhuizen, M. G., Felsted, J., Mak, Y. E., \& McGlone, F. (2008). Separable Substrates for Anticipatory and Consummatory Food Chemosensation. Neuron, 57(5), 786-797. http://doi.org/10.1016/j.neuron.2008.01.021

Smallwood, A., Estève, P.-O., Pradhan, S., \& Carey, M. (2007). Functional cooperation between HP1 and DNMT1 mediates gene silencing. Genes \& Development, 21(10), 1169-78. http://doi.org/10.1101/gad.1536807

Swanson, L. W. (2000). Cerebral hemisphere regulation of motivated behavior. Brain Research, 886(1), 113-164. http://doi.org/10.1016/S00068993(00)02905-X

Thiel, G. (1993). Synapsin I, Synapsin II, and Synaptophysin: Marker Proteins of Synaptic Vesicles. Brain Pathology, 3(1), 87-95. http://doi.org/10.1111/j.1750-3639.1993.tb00729.x

Torregrossa, M. M., Quinn, J. J., \& Taylor, J. R. (2008). Impulsivity, compulsivity, and habit: the role of orbitofrontal cortex revisited. Biological Psychiatry, 63(3), 253-5. http://doi.org/10.1016/j.biopsych.2007.11.014

Tschöp, M., Smiley, D. L., \& Heiman, M. L. (2000). Ghrelin induces adiposity in rodents. Nature, 407(6806), 908-913. http://doi.org/10.1038/35038090

Turton, M. D., O'Shea, D., Gunn, I., Beak, S. A., Edwards, C. M. B., Meeran, K., ... Bloom, S. R. (1996). A role for glucagon-like peptide-1 in the central regulation of feeding. Nature, 379(6560), 69-72. http://doi.org/10.1038/379069a0

Uher, R., Murphy, T., Brammer, M. J., Dalgleish, T., Phillips, M. L., Ng, V. W., ... Treasure, J. (2004). Medial Prefrontal Cortex Activity Associated With Symptom Provocation in Eating Disorders. American Journal of Psychiatry, 161(7), 1238-1246. http://doi.org/10.1176/appi.ajp.161.7.1238

Van den Eynde, F., Guillaume, S., Broadbent, H., Stahl, D., Campbell, I. C., Schmidt, U., \& Tchanturia, K. (2011). Neurocognition in bulimic eating disorders: a systematic review. Acta Psychiatrica Scandinavica, 124(2), 120-140. http://doi.org/10.1111/j.1600-0447.2011.01701.x

Veldic, M., Caruncho, H. J., Liu, W. S., Davis, J., Satta, R., Grayson, D. R., ... Costa, E. (2004). DNA-methyltransferase 1 mRNA is selectively overexpressed in telencephalic GABAergic interneurons of schizophrenia brains. Proceedings of the National Academy of Sciences of the United States of America, 101(1), 348-353.

Vertes, R. P. (2004). Differential projections of the infralimbic and prelimbic cortex in the rat. Synapse, 51(1), 32-58. http://doi.org/10.1002/syn.10279

Viré, E., Brenner, C., Deplus, R., Blanchon, L., Fraga, M., Didelot, C., ... Fuks, F. (2005). The Polycomb group protein EZH2 directly controls DNA methylation. Nature, 439(7078), 871-874.

http://doi.org/10.1038/nature04431

Vucetic, Z., Kimmel, J., \& Reyes, T. M. (2011). Chronic high-fat diet drives 
postnatal epigenetic regulation of $\mu$-opioid receptor in the brain.

Neuropsychopharmacology: Official Publication of the American College of Neuropsychopharmacology, 36(6), 1199-206.

http://doi.org/10.1038/npp.2011.4

Vucetic, Z., Kimmel, J., Totoki, K., Hollenbeck, E., \& Reyes, T. M. (2010). Maternal high-fat diet alters methylation and gene expression of dopamine and opioid-related genes. Endocrinology, 151(10), 4756-4764. http://doi.org/10.1210/en.2010-0505

Wang, J., Hevi, S., Kurash, J. K., Lei, H., Gay, F., Bajko, J., ... Chen, T. (2009). The lysine demethylase LSD1 (KDM1) is required for maintenance of global DNA methylation. Nature Genetics, 41(1), 125-129. http://doi.org/10.1038/ng.268

Wang, W.-Z., Oeschger, F. M., Lee, S., Molnár, Z., Emmert-Buck, M., Bonner, R., ... Liotta, L. (2009). High quality RNA from multiple brain regions simultaneously acquired by laser capture microdissection. BMC Molecular Biology, 10(1), 69. http://doi.org/10.1186/1471-2199-10-69

Weil, D., Boutain, S., Audibert, A., \& Dautry, F. (2000). Mature mRNAs accumulated in the nucleus are neither the molecules in transit to the cytoplasm nor constitute a stockpile for gene expression. RNA (New York, N.Y.), 6(7), 962-75. Retrieved from http://www.ncbi.nlm.nih.gov/pubmed/10917593

Wise, R. A. (1974). Lateral hypothalamic electrical stimulation: Does it make animals "hungry"? Brain Research, 67(2), 187-209. http://doi.org/10.1016/0006-8993(74)90272-8

Wise, R. A. (2004). Dopamine, learning and motivation. Nature Reviews Neuroscience, 5(6), 483-494. http://doi.org/10.1038/nrn1406

Wise, R. A. (2006). Role of brain dopamine in food reward and reinforcement. Philosophical Transactions of the Royal Society of London. Series B, Biological Sciences, 361(1471), 1149-58. http://doi.org/10.1098/rstb.2006.1854

Wolffe, A. P., Robertson, K. D., Ait-Si-Ali, S., Yokochi, T., Wade, P. A., \& Jones, P. L. (2000). DNMT1 forms a complex with Rb, E2F1 and HDAC1 and represses transcription from E2F-responsive promoters. Nature Genetics, 25(3), 338-342. http://doi.org/10.1038/77124

Woods, S. C., Lotter, E. C., McKay, L. D., \& Porte, D. (1979). Chronic intracerebroventricular infusion of insulin reduces food intake and body weight of baboons. Nature, 282(5738), 503-505. http://doi.org/10.1038/282503a0

Zeisel, A., Muñoz-Manchado, A. B., Codeluppi, S., Lönnerberg, P., La Manno, G., Juréus, A., ... Linnarsson, S. (2015). Cell types in the mouse cortex and hippocampus revealed by single-cell RNA-seq. Science, 347(6226). 